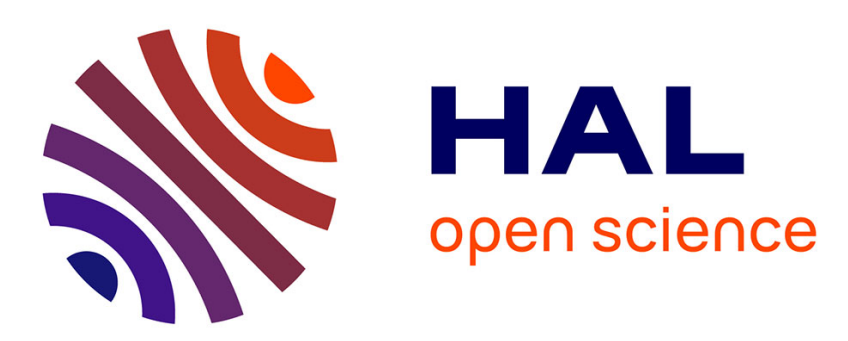

\title{
Oligopoly under incomplete information: on the welfare effects of price discrimination
}

Daniel F. Garrett, Renato Gomes, Lucas Maestri

\section{To cite this version:}

Daniel F. Garrett, Renato Gomes, Lucas Maestri. Oligopoly under incomplete information: on the welfare effects of price discrimination. International Journal of Industrial Organization, 2021, 79, 10.1016/j.ijindorg.2021.102735 . hal-03515749

\section{HAL Id: hal-03515749 \\ https://hal.science/hal-03515749}

Submitted on 6 Jan 2022

HAL is a multi-disciplinary open access archive for the deposit and dissemination of scientific research documents, whether they are published or not. The documents may come from teaching and research institutions in France or abroad, or from public or private research centers.
L'archive ouverte pluridisciplinaire HAL, est destinée au dépôt et à la diffusion de documents scientifiques de niveau recherche, publiés ou non, émanant des établissements d'enseignement et de recherche français ou étrangers, des laboratoires publics ou privés. 


\title{
Oligopoly under Incomplete Information: On the Welfare Effects of Price Discrimination*
}

\author{
Daniel Garrett ${ }^{\dagger} \quad$ Renato Gomes ${ }^{\ddagger} \quad$ Lucas Maestri ${ }^{\S}$
}

March, 2021

\begin{abstract}
We study competition by firms that simultaneously post (potentially nonlinear) tariffs to consumers who are privately informed about their tastes. Market power stems from informational frictions, in that consumers are heterogeneously informed about firms' offers. In the absence of regulation, all firms offer quantity discounts. As a result, relative to Bertrand pricing, imperfect competition benefits disproportionately more consumers whose willingness to pay is high, rather than low. Regulation imposing linear pricing hurts the former but benefits the latter consumers. While consumer surplus increases, firms' profits decrease, enough to drive down utilitarian welfare. By contrast, improvements in market transparency increase utilitarian welfare, and achieve similar gains on consumer surplus as imposing linear pricing, although with limited distributive impact. On normative grounds, our analysis suggests that banning price discrimination is warranted only if its distributive benefits have a weight on the societal objective.
\end{abstract}

JEL Classification: D 82

Keywords: oligopoly, nonlinear pricing, linear pricing, informational frictions, asymmetric information

${ }^{*}$ We would like to thank Leslie Marx and an anonymous referee for comments that greatly improved the paper. Daniel Garett has received funding from the European Research Council (ERC) under the European Union's Horizon 2020 research and innovation programme (grant agreement No. 714147). Renato Gomes gratefully acknowledges financial support from the European Research Council (ERC) under the European Union's Horizon 2020 research and innovation programme (grant agreement No. 759733). Daniel and Renato also acknowledge funding from the ANR under grant ANR-17-EURE-0010 (Investissements d'Avenir programme). Lucas Maestri acknowledges that this study was financed in part by the Coordenação de Aperfeiçoamento de Pessoal de Nivel Superior - Brasil (CAPES) Finance Code 001. Lucas Maestri is also grateful for financial support from CNPq National Council for Scientific and Technological Development.

${ }^{\dagger}$ Toulouse School of Economics, University of Toulouse Capitole: daniel.garrett@tse-fr.eu.

${ }^{\ddagger}$ Toulouse School of Economics, CNRS, University of Toulouse Capitole: renato.gomes@tse-fr.eu.

${ }^{\S}$ FGV EPGE Escola Brasileira de Economia e Finanças: lucas.maestri@fgv.br. 


\section{Introduction}

Nonlinear pricing (or second-degree price discrimination, in the terminology of Pigou 1920) is the practice whereby firms price each unit purchased of a good differently, leading to quantity discounts or premia. This practice is widespread in many industries, such as electricity, gas, telecommunications, and advertising, and it is also common across a range of consumer goods. Its distributive consequences, that is, its effects across different types of consumers, have long intrigued economists.

As Dupuit (1849) wrote:

It is not because of the few thousand francs which would have to be spent to put a roof over the third-class carriages or to upholser the third-class seats that some company or other has open carriages with wooden benches... What the company is trying to do is prevent the passengers who can pay the second class fare from traveling third-class; it hits the poor, not because it wants to hurt them, but to frighten the rich... And it is again for the same reason that the companies, having proved almost cruel to third-class passengers and mean to second-class ones, become lavish in dealing with first-class passengers. Having refused the poor what is necessary, they give the rich what is superfluous. [Translated from French by Ekelund (1970).]

Although formulated in terms of the quality/comfort of train rides, the reasoning of Dupuit equally applies to settings where firms offer quantity discounts, restricting the purchase of the poor (low willingness to pay), who face high marginal prices, but being magnanimous with the rich (high willingness to pay), who are given discounts for bulky purchases.

More recently, the negative distributive effects of price discrimination came to the fore of the regulatory debate. Concerns for equity motivated, for instance, the regulator to ban "declining-block pricing" (i.e., quantity discounts) for electricity in California (see Borenstein 2012) 11 Similar considerations have led to the imposition of social tariffs for gas and electricity in several European countries, requiring the utility companies to give discounts to the poor (those who have low consumption), effectively weakening (or entirely undoing) the quantity discounts originally in place $\mathrm{L}^{2}$ At the heart of these policies lies the belief that (unrestricted) nonlinear pricing leverages firms' market power and magnifies inequality across consumers (which is a salient issue in the debate on the regulation of utilities) $3^{3}$ In other settings, concerns about the undesirable affects of overconsumption can

\footnotetext{
${ }^{1}$ Levinson and Silva (2021) use a dataset of 1,300 utilities across the U.S. to show that, in areas where ratepayers have more unequal incomes, electricity providers are induced by local regulators to employ more "redistributive" tariffs.

${ }^{2}$ For general information about these initiatives in the European Union, visit https://www.energypoverty.eu/

${ }^{3}$ There are other rationales that might motivate departures from nonlinear pricing. Miravete (2007), in the context of the cellular telephone market in the US, argues that simplicity may motivate a monopolist to abandon complex nonlinear tariffs. Feger and Radulescu (2018) suggest that regulated electricity tariffs may also reflect environmental concerns.
} 
also play a role, as for instance in the Alcohol etc. (Scotland) Act 2010 which seeks to mitigate bulk purchases of alcohol by banning quantity discounts in certain Scottish outlets 4

While relevant for policy, little is known about the effects of nonlinear pricing, vis-à-vis tariff regulation, in oligopolistic settings. Part of the difficulty lies in having analytically tractable models of second-degree price discrimination under imperfect competition. This question has been taken up recently by Garrett, Gomes and Maestri (2019), for settings where imperfect competition arises due to imperfect observability of offers by consumers (equivalently, due to "limited consideration sets"). In this paper, we build on the equilibrium analysis of our earlier article to understand the welfare implications of nonlinear pricing, contrasting it to the situation where firms are constrained to offer linear tariffs, an important benchmark in light of the regulatory concerns discussed above.

\section{Model and Contribution of the Paper}

We develop our analysis in the context of the continuum-of-types setting of Garrett, Gomes and Maestri (2019), focusing on the situation where types are distributed uniformly on the unit interval. Section 2 describes this model, where firms oligopolistically compete for consumers by simultaneously posting tariffs (which are either unconstrained, or linear in the quantity purchased, depending on the regulatory regime). Consumers' private types index their preferences, which can be understood in terms of different marginal utility curves. As noted above, firms' market power stems from informational frictions, in that consumers are heterogeneously (and partially) informed about the offers available in the market.

Section 3 derives the equilibrium outcome under laissez-faire, where no restrictions are imposed on the firms' price schedules. As consumers face informational frictions, firms in equilibrium randomize over tariff schedules (that is, the equilibrium is in mixed strategies). Equilibrium tariffs are ordered, in that a more generous tariff charges a lower price for any given quantity. In equilibrium, firms are indifferent among all tariffs in the support of the mixed strategy, as more generous tariffs attract a larger demand while generating lower profits per sale.

Because the equilibrium marginal tariff schedules are weakly above cost (with equality only at the largest purchased quantity), consumers purchase inefficiently low quantities of the good (except those with the highest willingness to pay). More generous tariffs also exhibit a lower marginal tariff schedule (which describes the price of each marginal unit of the good). Distortions therefore decrease with the generosity of the tariff, as consumers get closer to their efficient purchasing level. Relatedly, a larger set of consumers is served under more generous tariffs, increasing efficiency.

A crucial feature of the equilibrium is that marginal tariff schedules are decreasing in quantity, that is, firms offer quantity discounts. This feature has striking distributive consequences. To analyze

\footnotetext{
${ }^{4}$ Section 2(2) of the Act states "A package containing two or more alcoholic products (whether of the same or different kinds) may only be sold on the premises at a price equal to or greater than the sum of the prices at which each alcoholic product is for sale on the premises."
} 
these, we construct a benchmark by fixing informational frictions (in particular, allowing consumers with bad luck to be knowledgeable of no firm), while assuming that firms post the Bertrand tariff (selling each quantity of the good at cost). In a plausible scenario $5^{5}$ consumers with the highest willingness to pay obtain in equilibrium around $87 \%$ of their benchmark payoff, while those consumers with willingness to pay in the 20-th percentile of the taste distribution obtain around $25 \%$ of their benchmark payoff (as they buy few units of the good, facing high marginal tariffs). This finding echoes the comments of Dupuit, in that price discrimination induces firms to be "cruel to third-class passengers and mean to second-class ones", while being (perhaps with some exaggeration) "lavish with the rich."

In light of the rather unequal effects of price discrimination across consumers, we analyze in Section 4 the equilibrium outcome were the regulator to impose linear pricing, therefore preventing quantity discounts. Similarly to laissez-faire, firms in equilibrium randomize over tariffs (now linear). Low per-unit prices attract more customers but generate lower profits per sale, rendering firms indifferent across all equilibrium tariffs.

The uniformity of marginal prices implies that all consumers (including those with high willingness to pay) purchase an inefficiently low quantity. This allocative distortion is accompanied, however, with greater inclusiveness, in that firms in equilibrium serve a larger range of consumers.

Section 5 compares the outcomes under laissez-faire and linear pricing. Intuitively, the inability to price discriminate pushes firms to compete less intensively for the "rich," who obtain (probabilistically) lower payoffs. Being unable to generate (as much) profits from the "rich," firms under linear pricing compete more fiercely for the "poor," who (probabilistically) benefit from this policy.

In the same plausible scenario alluded to above, consumers with the highest willingness to pay obtain in the linear-pricing equilibrium around $85 \%$ of their benchmark payoff, while those consumers with willingness to pay in the 20-th percentile of the taste distribution now obtain around $42 \%$ of their benchmark payoff (in comparison to only 25\% under laissez-faire). Accordingly, linear pricing provides significant gains to the latter consumers, while only modestly hurting those consumers with the highest willingness to pay.

Aggregating over types, consumer surplus slightly increases (by $3 \%$ in the aforementioned scenario) due to linear pricing. Firms however suffer when exposed to this regulation. Namely, their profits fall by around $11 \%$. This is enough to generate a small reduction in utilitarian welfare (by about $0.1 \%$ in the scenario of Footnote 5$)$.

To place these welfare effects in a broader context, we compare them to variations in informational frictions, which drive firms' market power in our setting. ${ }^{6}$ In the same plausible scenario as

\footnotetext{
${ }^{5}$ Namely, assuming firms have quadratic costs, that consumer types are uniformly distributed in the unit interval, and that the size of each consumer's sample of firms is distributed à la Poisson with an average of 1.5.

${ }^{6}$ Regulators around the wold are increasingly favoring policies aiming at increasing market transparency. One early example comes from the UK regulator for gas and electricity (Ofgem), which promotes and accredits price comparison
} 
above, a slight increase in the average size of consumers' sample, from 1.5 to 1.6, is enough to generate the same gains in aggregate consumer surplus. This comparison suggests that market transparency is more consequential for aggregate consumer surplus than regulation imposing linear pricing.

All in all, improvements in market transparency, although increasing utilitarian welfare and aggregate consumer surplus, have relatively limited distributive effects.7 7 For instance, in the aforementioned scenario, the average sample size of consumers would have to increase from 1.5 to 1.9 to match the gains from linear pricing enjoyed by consumers the 20-th percentile of the taste distribution. Although generating distortions (absent under laissez-faire) in the consumption of buyers with the highest willingness to pay, our analysis indicates that linear pricing is an effective redistributive tool. This accords with the use of social tariffs (which renders the marginal tariffs closer to uniform) in utility regulation, where distributive concerns play an important role in the policy debate.

\section{$1.1 \quad$ Related Literature}

The seminal contributions of Armstrong and Vickers (2001) and Rochet and Stole (2002) consider settings where market power stems from firms being horizontally differentiated. These papers find that, if competition is sufficiently intense, firms do not engage in price discrimination, offering costplus-fee tariffs (which generate constant markups). This prediction contrasts with the reality in many industries, and finds little empirical support (e.g., Verboven 1999) 8 By contrast, our modeling approach delivers a laissez-faire outcome that is closer to practice (in that firms actively engage in price discrimination), is more tractable (covering the whole spectrum of competitive intensity), and allows for a straight-forward comparison to transparency-promoting policies (currently en vogue among regulators). We refer the reader to Stole (2007) and Garrett, Gomes and Maestri (2019) for a thorough discussion of models of competition in nonlinear pricing, focusing instead here on the literature on tariff regulation.

Wilson (1993) is a seminal reference on this regard. He notes (on page 104) that regulatory agencies are "cautious in allowing tariffs that involve price discrimination, in part to ensure they are not sustained by quality degradation or other sources of productive or allocative inefficiencies." Rather than its effects on allocative (in)efficiency, our focus here are on the distributive effects of nonlinear pricing, specially among consumers.

sites. See https://www.ofgem.gov.uk/consumers/household-gas-and-electricity-guide/how-switch-energy-supplier-andshop-better-deal/compare-gas-and-electricity-tariffs-ofgem-accredited-price-comparison-sites

${ }^{7}$ In line with this finding, the French Competition Authority, justifying the imposition of social tariffs, stated that "Vulnerable customers on the social electricity tariff are not able to benefit from competition, unlike other customers." See https://www.autoritedelaconcurrence.fr/en/communiques-de-presse/8-march-2012-social-energy-tariffs.

${ }^{8}$ Gomes, Lozachmeur and Maestri (2020) revisit the horizontal-differentiation approach allowing for comovements between consumers' taste for quality and propensity to switch brands. Cost-plus-fee tariffs occur in equilibrium only if all consumers exhibit the same propensity to switch brands. They offer a complete characterization away from this knife-edge case. 
Concerns about the effects of price discrimination on consumers' payoffs might contrast with the received wisdom from Ramsey (1927), who famously established that maximization of consumers surplus, subject to the monopolist covering costs, entails consumers with a lower demand elasticity facing higher prices. Indeed, as articulated by Wilson (1993), the insight from Ramsey can be readily applied to second-degree price discrimination, provided one interprets the problem of the regulator as that of choosing a sequence of prices for each unit purchased. Formulated in terms of the demand elasticity of each marginal quantity, Ramsey's analysis leads precisely to nonlinear pricing.

At the root of this apparent discrepancy lies the requirement, inherent to Ramsey's formulation, that the firm reaches a minimum revenue requirement (covering costs). In the absence of revenue targets, which is typically the norm in the modern regulation of oligopoly, Ramsey's argument for differentiated pricing has no bite. Consequently, there are no a priori reasons to reject imposing linear pricing, which renders uniform the price of marginal units. Indeed, we show that regulation imposing linear pricing may increase consumer surplus, although reducing firms' profits, besides being an effective tool for redistribution.

Our paper is related to theoretical work examining the role of price discrimination in competitive markets. Much of this work is focused on antitrust concerns surrounding the use of nonlinear pricing as a means of exclusion by a dominant firm. For instance, Carlton and Waldman (2008) write that "the focus of an economist's search for antitrust harm should be primarily, if not exclusively, on cases where a rival is so deprived of scale that it either goes out of business or suffers significant impairment of its competitive influence." Relatedly, Calzolari and Denicolò (2013) consider a setting with symmetric firms and assess the welfare impact of exclusive contracts and market-share discounts. Assuming one firm is dominant, Calzolari and Denicolò (2015) analyze the effect of exclusive dealing.

The closest in spirit to the present paper is Calzolari and Denicolò (2011) who analyze nonlinear and linear pricing in a model of competitive pricing due to Martimort and Stole (2009), where there are two sellers of differentiated products which are imperfectly substitutable, and where (unlike our paper) consumers may buy from either or both sellers. When competing firms are symmetric, Calzolari and Denicolò (2011) find that a restriction to linear pricing hurts consumers if products are closer substitutes, but helps them otherwise. By contrast, under exclusive purchases, perfect product substitutability but imperfect consumer information, we find that the imposition of linear pricing increases consumer surplus.

Much of the empirical interest in comparing quantity discounts and uniform pricing is focused on intermediate goods markets, where the presence of a downstream market needs to be explicitly taken into account. Examples include Villas-Boas (2009), Grennan (2013), and Hagemann (2018). An exception is Crawford and Yurukoglu (2012), who consider the effect of mandating à la carte pricing in offers to final consumers.

More broadly, our article contributes to the emerging literature on how to design markets when 
the social welfare function exhibits preferences for equity. Unlike the recent contribution of Dworczak, Akbarpour and Kominers (2020), who search for the optimal mechanism in a competitive setting, we endow firms with market power and compare laissez-faire to a specific market mechanism (competition under linear pricing).

\section{$2 \quad$ Model and Preliminaries}

The economy is populated by $M \in \overline{\mathbb{N}}$ consumers who differ in their preferences for the consumption of a homogeneous good $\sqrt[9]{9}$ Namely, we assume that, if a consumer with type $\theta$ purchases $q$ units of the good at a price $p$, her utility is

$$
\int_{0}^{q} \max \{\theta-\tilde{q}, 0\} d \tilde{q}-p
$$

Accordingly, $\theta$ indexes the consumers' marginal utility of consumption for the good, which is decreasing in the quantity purchased 10 Note that the gross utility of a type- $\theta$ consumer is maximized by purchasing $q=\theta$ units. Consumer types are iid draws from a uniform distribution in the unit interval $[0,1]$.

There are $N \in \overline{\mathbb{N}}, N \geq 2$, firms in the market. Firms do not observe consumer types and compete by posting direct-revelation mechanisms $\mathcal{M} \equiv((q(\theta), p(\theta)): \theta \in[0,1])$, where $q(\theta)$ is the quantity, and $p(\theta)$ is the price of the contract designed for type $\theta$. Firms incur a constant marginal cost, which we normalize to zero. Accordingly, the per-sale profit of a contract $(q(\theta), p(\theta))$ is simply $p(\theta)$.

A menu is incentive compatible if each type- $\theta$ consumer prefers contract $(q(\theta), p(\theta))$ to all other options in the menu. It is individually rational if all consumers obtain non-negative utility from their respective contracts. The set of incentive compatible and individually rational menus (which we call implementable) is denoted by $\mathbb{I}$.

In the case of laissez-faire, no restrictions are imposed on the implementable menus firms can choose from. Accordingly, a strategy for a firm is a (possibly degenerate) distribution $\mathbf{F}$ over the set of implementable menus $\mathbb{I}$. If linear pricing is imposed, consumers may purchase any quantity at a constant price per unit. Firms are therefore restricted to choose from the subset of implementable menus for which there exists a linear price $\tau \in \mathbb{R}$ such that $p(\theta)=\tau q(\theta)$ for all $\theta \in[0,1]$. Denoting by $\mathbb{L}$ the class of such menus, a strategy for a firm is then a (possibly degenerate) distribution $\mathbf{F}$ over the set $\mathbb{L} \subset \mathbb{I}$.

Consumers are heterogeneous in their information about market offers. Namely, each consumer observes a sample of firms which size is a draw (iid across consumers) from the distribution $\Omega \equiv$ $\left\{\omega_{s}: s=0,1,2, \ldots, N\right\}$. To keep the model interesting, we assume each consumer observes a single

\footnotetext{
${ }^{9} \overline{\mathbb{N}}$ stands for the extended natural numbers; namely, $\overline{\mathbb{N}}=\mathbb{N} \cup\{+\infty\}$.

${ }^{10}$ This specification of preferences is common in the literature; see Maskin and Riley (1984) and Wilson (1993).
} 
firm, or at least two firms, with positive probability: $\omega_{1} \in(0,1)$ and $\omega_{s} \in(0,1)$ for some $s \geq 2$. All firms are equally likely to belong to each consumer's sample.

A symmetric equilibrium (from hereon, equilibrium) under laissez-faire (resp., in linear pricing) is a distribution $\mathbf{F}$ over menus in $\mathbb{I}$ (resp., $\mathbb{L}$ ) such that each contract in the support of $\mathbf{F}$ maximizes profits over all menus in $\mathbb{I}$ (resp., $\mathbb{L}$ ) when all other firms follow the strategy $\mathbf{F}$.

\subsection{Demands}

Suppose firms randomize over menus according to some distribution F. For a given menu in the support of $\mathbf{F}$, let $u(\theta)$ describe the indirect utility obtained by type $\theta$. We denote by $F(u(\theta), \theta)$ the probability assigned by $\mathbf{F}$ to menus that deliver indirect utility less than $u(\theta)$ to type $\theta$. Accordingly, $y=F(u(\theta), \theta)$ is the type- $\theta$ quantile of menu $u$. Whenever $y$ is a continuity point of $F(\cdot, \theta){ }^{11}$ the demand by type- $\theta$ consumers for this menu is given by

$$
\Lambda(y) \equiv \nu \sum_{s=1}^{N} s \omega_{s} y^{s-1},
$$

where $\nu$ is the ratio of consumers to firms. We are interested in the cases where $0<\nu<\infty$. Accordingly, the number of consumers, $M$, is finite if and only if the number of firms, $N$, is also finite, in which case $\nu=\frac{M}{N}$. Conversely, we write that $M=N=\infty$ to represent the case where there is a continuum of consumers of measure $\nu$ and a continuum of firms of measure 1 . The next examples describe important special cases of our model.

Example 1 [Poisson] Let $M=N=\infty$ and the distribution $\Omega$ be Poisson with parameter $\lambda$, where $\lambda>012$ Because a random variable distributed à la $\Omega$ has mean $\lambda$, we identify the latter with the average number of offers observed by consumers. In this case, demands are

$$
\Lambda(y)=\nu \lambda \exp \{-\lambda(1-y)\}
$$

Example 2 [Binomial] Let $M$ and $N$ be finite, and $N \geq 2$. Let the distribution $\Omega$ be binomial with parameter $\delta \in(0,1) 13$ In this case, the parameter $\delta$ describes the probability that each consumer observes each individual firm. Demands are then given by

$$
\Lambda(y)=M \delta(1-\delta+\delta y)^{N-1}
$$

\footnotetext{
${ }^{11}$ More generally, if $y$ a mass point, we assume that firms split demand evenly. We will confirm that, in equilibrium, for all $\theta$, the $\operatorname{cdf} F(\cdot, \theta)$ has support on an interval and is indeed continuous over its support. In the text, we focus on the case in which there is no mass point to simplify the exposition.

${ }^{12}$ Namely, $\omega_{s}=\lambda^{s} \exp \{-\lambda\} \frac{1}{s !}$ with $s \in\{0,1,2, \ldots\}$.

${ }^{13}$ Namely, $\omega_{s}=\frac{N !}{s !(N-s) !} \delta^{s}(1-\delta)^{N-s}$ with $s \in\{0,1,2, \ldots, N\}$.
} 
Example 3 [Geometric] Let $M=N=\infty$ and the distribution $\Omega$ be geometric with parameter $\gamma \in(0,1) 1^{14}$ Because a random variable distributed à la $\Omega$ has mean $\frac{\gamma}{1-\gamma}$, we identify $\gamma$ with the average number of offers observed by consumers. In this case,

$$
\Lambda(y)=\nu \gamma\left(\frac{1-\gamma}{(1-\gamma y)^{2}}\right)
$$

Each firm's demand (from consumers of any type) is naturally increasing and continuous in the quantile occupied by the firm's offer.

\section{$3 \quad$ Equilibrium under Laissez-Faire}

We start by considering the firms' problem when no restrictions are imposed in their price schedules.

\subsection{Firms' Problem}

By standard arguments, a menu $\mathcal{M}$ is incentive compatible (IC) if and only if the indirect utility schedule $u(\cdot)$ is absolutely continuous (with derivative $u^{\prime}(\theta)=q(\theta)$ almost everywhere) and convex. For convenience, and in light of incentive compatibility, we write $\mathcal{M}=u(\cdot)$ to describe the menu $\mathcal{M} \equiv((q(\theta), p(\theta)): \theta \in[0,1])$, where $q(\theta)=u^{\prime}(\theta)$ and $p(\theta)=\theta u^{\prime}(\theta)-\frac{1}{2}\left[u^{\prime}(\theta)\right]^{2}-u(\theta)$ for almost every $\theta$.

To derive an equilibrium, consider the problem of a firm which competitors randomize over menus according to some (possibly degenerate) distribution F. The firm's profit from the menu $u(\cdot)$ is then given by

$$
\pi[u] \equiv \int_{0}^{1} \Lambda(F(u(\theta) ; \theta))\left(\theta u^{\prime}(\theta)-\frac{1}{2}\left[u^{\prime}(\theta)\right]^{2}-u(\theta)\right) d \theta .
$$

The expression in (2) integrates over all types $\theta \in[0,1]$ the product of demand, $\Lambda(F(u(\theta) ; \theta)$ ), and profit per sale, $p(\theta)$.

\subsection{Equilibrium}

By familiar arguments from models of price dispersion under complete information (e.g., Varian (1980)), no pure-strategy equilibrium exists. We therefore look for a mixed-strategy equilibrium. In any such equilibrium, the objective (2) admits a continuum of maximands; all of which generate equal profit. We focus on ordered equilibria, as introduced by Garrett, Gomes, and Maestri (2019).

Definition 1 [Ordered Equilibrium] An equilibrium is said to be ordered if the distribution over menus $\mathbf{F}^{*}$, whose support is denoted by $\mathbb{S}$, is such that:

(a) $\mathcal{M}=u(\cdot) \in \mathbb{S} \subseteq \mathbb{I}$ implies that $\mathcal{M}=u(\cdot)$ maximizes (2),

\footnotetext{
${ }^{14}$ Namely, $\omega_{s}=\gamma^{s}(1-\gamma)$ with $s \in\{0,1,2, \ldots\}$.
} 
(b) if $u(\cdot), \hat{u}(\cdot) \in \mathbb{S}$, and $u(\tilde{\theta})>\hat{u}(\tilde{\theta})$ for some $\tilde{\theta} \in[0,1]$, then $u(\theta) \geq \hat{u}(\theta)$ for all $\theta \in[0,1]$, with strict inequality whenever $u(\theta)>0$.

The first condition in the definition above is the usual profit-maximization requirement. The second condition captures the "ordered" feature of our equilibrium: If a menu is "more generous" to one type of consumer, then it is more generous to all consumer types that are served by that menu. Accordingly, whenever positive, the indirect utilities offered to different consumer types co-move across menus. In light of this property, we shall abuse terminology and identify a menu by $\bar{u}$, which is indirect utility left to consumers with the highest type $\theta=115$

We denote by $V(\theta, \bar{u})$ the indirect utility received by type $\theta$ in the menu $\bar{u}$. For a given ordered equilibrium, we refer to the bivariate function $V(\cdot, \cdot)$ as its support schedule. Note that $V(\theta, \bar{u})$ is strictly increasing in $\bar{u}$ at every type $\theta$ that is not excluded (i.e, for which $V(\theta, \bar{u})>0$ ).

The next proposition characterizes an ordered equilibrium 16

Proposition 1 [Equilibrium: Nonlinear Pricing] There exists an ordered equilibrium $\mathbf{F}^{*}$. In this equilibrium, the indirect utilities offered by firms are described by the support schedule

$$
V^{*}(\theta, \bar{u})=\left\{\begin{array}{cl}
\frac{1}{4 \bar{u}}(\theta-1)^{2}+(\theta-1)+\bar{u} & \text { if } \theta \geq 1-2 \bar{u} \\
0 & \text { if } \theta<1-2 \bar{u}
\end{array}\right.
$$

with domain on $[0,1] \times\left[\frac{1}{4}, \frac{1}{2}\right)$. Moreover, the distribution over indirect utilities left to the highest type, denoted by $F^{*}(\bar{u} ; 1)$, solves the following equation in $y$ :

$$
\frac{\Lambda(y)}{\Lambda(0)}=\frac{1}{8 \bar{u}(1-2 \bar{u})}
$$

The support of $F^{*}(\bar{u} ; 1)$ is $\left[\frac{1}{4}, \overline{\bar{u}}\right]$, where $\overline{\bar{u}}$ uniquely solves $F^{*}(\overline{\bar{u}} ; 1)=1$.

In the equilibrium of Proposition 1, firms randomize over ordered menus. The least generous menu is the monopoly (or Mussa and Rosen, 1978) one, which delivers indirect utility $\bar{u}=\frac{1}{4}$ to consumers with the highest valuation for quality $(\theta=1)$. The menu $\bar{u}=\frac{1}{2}$ is the perfectly competitive (or Bertrand) menu. As consumers appropriate the full surplus in this menu, it constitutes an upper bound on firms' generosity. More generous menus generate higher indirect utility to all consumers

\footnotetext{
${ }^{15}$ Ordered equilibria appear naturally in environments in which the type space is finite. The reason is that offering a more generous contract to one type of consumer relaxes downward incentive-compatibility constraints, making it more profitable to increase the utility of the type below. In the related setting studied by Garrett, Gomes, and Maestri (2019), if consumer types belong to a discrete support, there exists a unique equilibrium, which is ordered, provided all downward adjacent incentive constraints bind. The latter condition is satisfied by construction with a continuum of types. For this reason, we conjecture that the ordered equilibrium described in Proposition 1 is the unique equilibrium of the game. A formal proof is however elusive.

${ }^{16}$ Although the setup of this paper is different, Proposition 1 is close to a result proved in the Online Appendix of Garrett, Gomes, and Maestri (2019).
} 

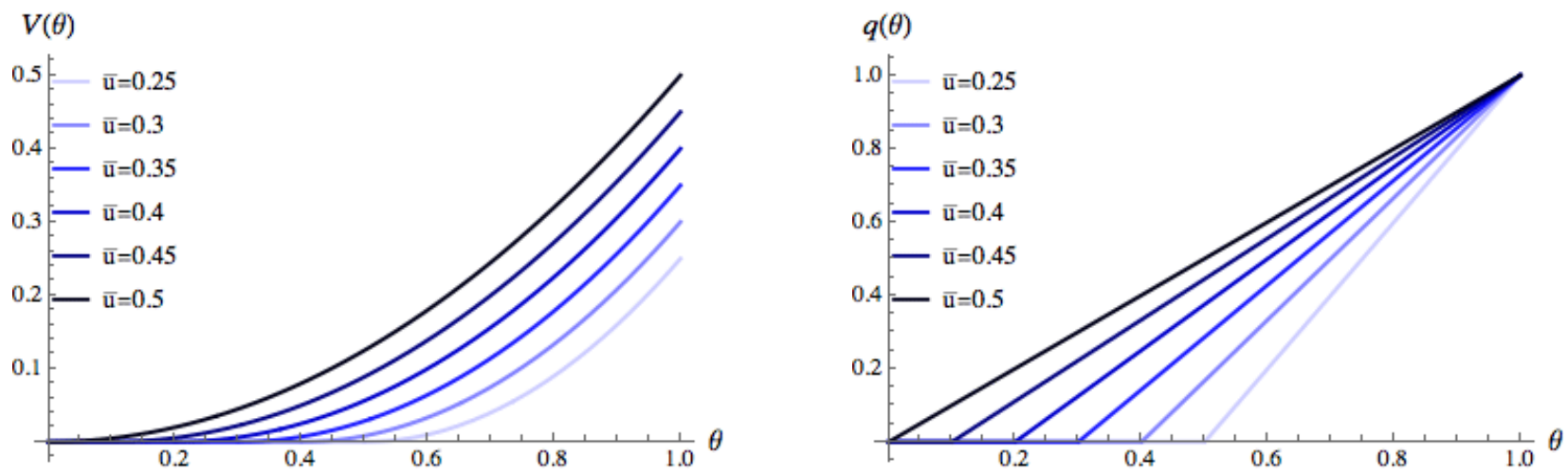

Figure 1: The support schedules (left-side panel) and quantity schedules (right-side panel) associated with different degrees of generosity.

who buy positive quantities. This is manifested in the fact that the support schedule $V^{*}(\theta, \bar{u})$ is strictly increasing in $\bar{u}$ at all $\theta$ for which $V^{*}(\theta, \bar{u})>0$. See Figure 1 (left-side panel) for an illustration.

More generous menus generate a larger demand but smaller profits per sale. Equation (4) is an indifference condition, guaranteeing that firms obtain the same expected profits from all menus in the support. This profit coincides with that of the monopolist menu (which generates the lowest volume of sales but the highest profit per sale for each type).

By incentive compatibility, the quality offered to type $\theta$ by menu $\bar{u}$, denoted by $q^{*}(\theta, \bar{u})$, is given by

$$
q^{*}(\theta, \bar{u})=V_{1}^{*}(\theta, \bar{u})=\max \left\{1-\left(\frac{1-\theta}{2 \bar{u}}\right), 0\right\} .
$$

Notice that $q^{*}(\theta, \bar{u})>0$ if and only if $\theta>1-2 \bar{u}$. We refer to $(1-2 \bar{u}, 1]$ as the service range of menu $\bar{u}$. All types outside of this range are excluded by the menu $\bar{u}$ (i.e., are assigned a zero utility, as their "preferred" contract is the one offering a zero quantity for zero payment). More generous menus serve a larger range of consumer types. Note however that not all menus in the range $\bar{u} \in\left[\frac{1}{4}, \frac{1}{2}\right]$ are offered in equilibrium; namely, only those satisfying $\bar{u} \in\left[\frac{1}{4}, \overline{\bar{u}}\right]$, where $\overline{\bar{u}}$ in the upper limit of the support of $F^{*}(\bar{u} ; 1)$.

Note that whenever type $\theta$ is served under the menu $\bar{u}$ (that is, $q^{*}(\theta, \bar{u})>0$ ) we have that $q^{*}(\theta, \bar{u}) \leq q^{e}(\theta)=\theta$, with strict inequality if and only if $\theta<1$. This means that all consumer types (except the top one) purchase an inefficiently low quantity in all menus offered by firms. These quantity (downward) distortions decrease (in magnitude) as the menu under consideration becomes more generous, in that

$$
q^{e}(\theta)-q^{*}(\theta, \bar{u})=\theta-\left[1-\left(\frac{1-\theta}{2 \bar{u}}\right)\right]
$$

is decreasing in $\bar{u}$. This quantity is also decreasing in $\theta$, revealing that higher types face lower 

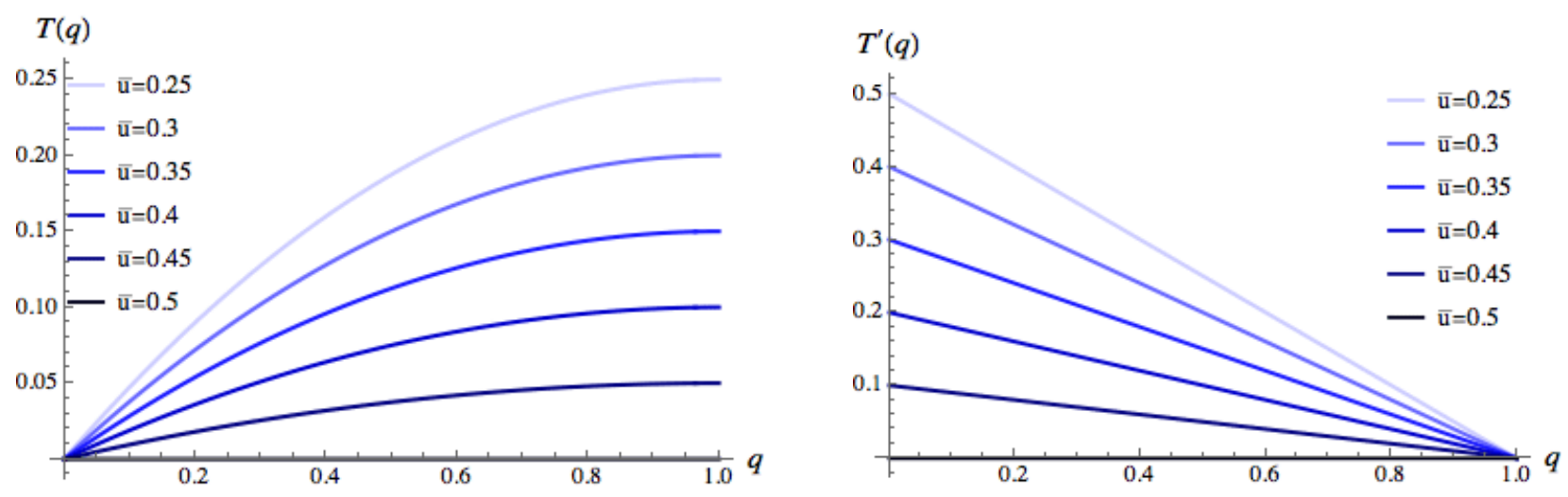

Figure 2: The tariff schedules (left-side panel) and marginal tariff schedules (right-side panel) associated with different degrees of generosity.

distortions. The right-side panel of Figure 1 illustrates the quantity schedules $q^{*}(\theta, \bar{u})$ implied by different menus.

Proposition 1 can be readily employed to derive the distributions of indirect utilities obtained by all consumer types. Indeed, by the ordered property of the equilibrium, for any $\theta \in(1-2 \bar{u}, 1]$,

$$
F^{*}(\bar{u} ; 1)=F^{*}(V(\theta, \bar{u}) ; \theta)
$$

Accordingly, if the menu $\bar{u}$ 's indirect utility to the highest type $\theta=1$ (which is simply $\bar{u}$ ) lies in quantile $F^{*}(\bar{u} ; 1)$, then the menu $\bar{u}$ 's indirect utility for any type in its service range $\theta \in(1-2 \bar{u}, 1]$ lies at the same quantile $F^{*}(\bar{u} ; 1)$.

For analytical convenience, Proposition 1 characterized the equilibrium in terms of directrevelation menus. The next corollary offers perhaps a more intuitive description of the equilibrium in terms of price-quantity tariffs.

Corollary 1 [Equilibrium: Indirect Implementation] The equilibrium $\mathbf{F}^{*}$ from Proposition 1 can be indirectly implemented by firms randomizing over the tariffs

$$
T^{*}(q ; \bar{u})=(1-2 \bar{u})\left(q-\frac{q^{2}}{2}\right)
$$

where $\bar{u}$ is distributed according to $F^{*}(\bar{u} ; 1)$.

In the formulation of Corollary 1, firms randomize over tariffs (mapping the quantity purchased into a transfer). Interestingly, tariffs in the equilibrium support are ordered, in that more expensive firms charge more for all quantities in the relevant range. See Figure 2 (left-side panel) for an illustration.

Importantly, firms actively engage in price discrimination, in that marginal quantities are charged different prices by all tariffs offered in equilibrium. This is illustrated in the right-side panel of Figure 
2, which plots the marginal tariff schedule

$$
\frac{\partial T^{*}}{\partial q}(q ; \bar{u})=(1-2 \bar{u})(1-q)
$$

at different generosity levels. Because $\bar{u}<\frac{1}{2}$ in all equilibrium menus, the marginal schedule $\frac{\partial T^{*}}{\partial q}$ is decreasing in $q$. Accordingly, "low" quantities face a larger marginal price than "high" quantities (i.e., consumers are offered quantity discounts). Interestingly, more generous tariffs are "closer" to being linear in the quantity demanded, in that the marginal tariff schedule is flatter.

\subsection{Comparative Statics}

The market power enjoyed by firms stems from consumers' heterogeneous (and partial) information about market offers. In this light, the next definition identifies the level of transparency in the market with properties of the sample size distribution $\Omega$. This is manifested in the demand $\Lambda$ faced by firms.

Definition 2 [Market Transparency] Let $\Lambda$ (resp., $\hat{\Lambda}$ ) be the demand under the distribution over sample sizes $\Omega$ (resp, $\hat{\Omega}$ ), as defined in equation (1). The degree of market transparency is higher under $\Omega$ than under $\hat{\Omega}$ if $\frac{\Lambda(y)}{\Lambda(0)}>\frac{\hat{\Lambda}(y)}{\hat{\Lambda}(0)}$ for all $y \in(0,1]$.

Accordingly, as consumer information changes, there is more market transparency if the gain from posting an offer at any quantile $y>0$, relative to the worst possible offer, increases. A sufficient condition in terms of the distribution over sample sizes $\Omega$ and $\hat{\Omega}$ is that $\frac{\omega_{s}}{\omega_{1}}>\frac{\hat{\omega}_{s}}{\hat{\omega}_{1}}$ for all $s \geq 2$. The latter is implied by likelihood ratio dominance 17

How does an improvement in market transparency affect the firms' equilibrium behavior and consumers' payoffs? The next example answers this question in a special case of our model.

Example 4 [Poisson] Consider the Poisson case from Example 1. The degree of market transparency is then captured by the parameter $\lambda$, as the ratio $\frac{\Lambda(y)}{\Lambda(0)}$ is strictly increasing in $\lambda$ for all $y \in(0,1]$. Employing Proposition 1, we obtain that distribution over firms' generosity is given by

$$
F^{*}(\bar{u} ; 1)=\frac{1}{\lambda} \ln \left(\frac{1}{8 \bar{u}(1-2 \bar{u})}\right)
$$

with support over $\left[\frac{1}{4}, \overline{\bar{u}}\right]$, where $\overline{\bar{u}}$ satisfies $e^{-\lambda}=8 \overline{\bar{u}}(1-2 \overline{\bar{u}})$. Clearly, as $\lambda$ increases, the cdf $F^{*}(\bar{u} ; 1)$ shifts according to first-order stochastic dominance. Accordingly, firms are more likely to offer more generous menus. By the ordered property of the equilibrium, it then follows that the expected consumer surplus increases in $\lambda$ (for all types served by some equilibrium menu).

\footnotetext{
${ }^{17}$ The likelihood-ratio order is commonly used in economics (see Jewitt (1991) for a detailed account). For discrete random variables, we say that $X$ dominates $\hat{X}$ in the sense of the likelihood-ratio order if $\frac{\rho(x)}{\hat{\rho}(x)}$ is increasing in $x$ over the union of the supports of $X$ and $\hat{X}$, where $\rho$ and $\hat{\rho}$ are the probability mass functions of $X$ and $\hat{X}$.
} 
Similar observations are found also for Examples 2 and 3 above, taking $\delta$ and $\gamma$, respectively, as parameters indexing market transparency. The next corollary shows that the conclusions of the example hold true more generally. It also reveals that, as the degree of market transparency increases, the range of consumer types served in equilibrium expands.

Corollary 2 [Comparative Statics] Suppose the degree of market transparency increases. Then:

(a) Firms offer more generous menus, in that the distribution of generosity $F^{*}(\bar{u} ; 1)$ increases in the sense of first-order stochastic dominance.

(b) The range of types served in equilibrium expands.

(c) The expected consumer surplus increases for all types, strictly so for those served by some equilibrium menu.

Although, by Corollary 2, market transparency weakly benefits all consumers, its effect is fairly heterogeneous across types. To analyze this issue, let us define the ex-ante consumer surplus of type $\theta$ under laissez-faire according to

$$
C S^{*}(\theta) \equiv \sum_{s=1}^{N} \omega_{s}\left(\int_{\frac{1}{4}}^{\overline{\bar{u}}} V^{*}(\theta, \bar{u}) d\left(F^{*}(\bar{u} ; 1)\right)^{s}\right) .
$$

The expression above describes the expected indirect utility of a consumer of type $\theta$ that selects her most generous offer for each realization of the sample size distribution.

As a benchmark for comparison, consider the situation where all firms post the Bertrand schedule, which relinquishes all surplus to consumers. The expected consumer surplus is then

$$
C S^{e}(\theta) \equiv\left(1-\omega_{0}\right) V^{*}\left(\theta, \frac{1}{2}\right) .
$$

Note that, in comparing $C S^{*}(\theta)$ and $C S^{e}(\theta)$, we hold constant the informational frictions faced by consumers, who might still have the bad luck of observing no offers.

Figure 3 plots the ratio

$$
r^{*}(\theta) \equiv \frac{C S^{*}(\theta)}{C S^{e}(\theta)},
$$

which describes the fraction of the ex-ante surplus under Bertrand pricing appropriated by consumers in equilibrium. Specifically, we adopt the Poisson specification of Example 1, and consider various degrees of market transparency. While (imperfect) competition greatly benefits high types, who appropriate a large percentage of their Bertrand-pricing payoff, low types fare much worse. Indeed, the highest type obtains around $77 \%$ of her Bertrand-pricing payoff, while the lowest types obtain nothing (as they are excluded by all firms in equilibrium) when consumers observe on average 0.75 offers. We obtain similar results when sample sizes are distributed binomially or geometrically (as described in Examples 2 and 3, respectively). 


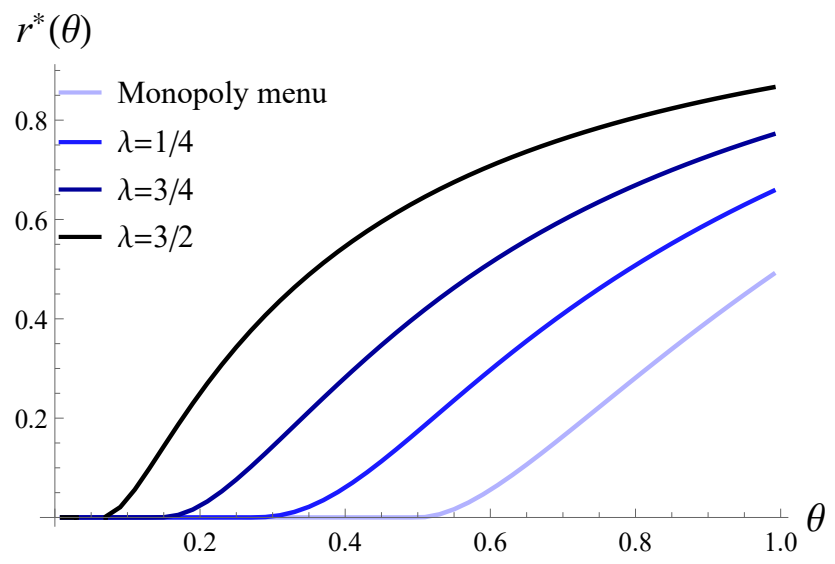

Figure 3: The schedule $r^{*}(\theta)$ for different degrees of market transparency under the Poisson parametrization.

\section{Equilibrium under Linear Pricing}

The last section studied oligopolistic competition when firms are not restricted in the tariffs they can employ. Because consumers are imperfectly informed about available offers, firms enjoy some market power, being therefore able to extract part of the consumer surplus. The effect of firms' market power is however heterogeneous across consumers: While firms relinquish some of their welfare contribution to high-type consumers, low types are severely hurt by the equilibrium tariffs. Indeed, these types are often excluded, or purchase substantially less than under perfect competition. This a consequence of the fact that firms actively price discriminate in equilibrium, as the equilibrium tariffs charge a higher marginal price for smaller than larger quantities.

In light of the rather unequal benefits of (imperfect) competition across consumer types, regulators often contemplate the possibility of limiting the firms' ability to price discriminate (for instance, by mandating the use of social tariffs, which give discounts to poor households). These policies render firms' tariffs close to linear (equalizing the unit price across marginal quantities). Intuitively, linear pricing should reduce the marginal price charged to small quantities, but increase that of large quantities, therefore favoring low-type consumers. The overall impact on consumers surplus is however unclear, as a the imposition of linear pricing changes how firms compete, potentially hindering their incentives to fight aggressively for consumers.

In order to assess these trade-offs, we first derive the unique equilibrium under linear pricing. In parallel to Proposition 1, our characterization is in the indirect-utility space.

Proposition 2 [Equilibrium: Linear Pricing] There exists a unique equilibrium $\mathbf{F}^{\dagger}$, which is ordered. In this equilibrium, the indirect utilities offered by firms are described by the support 
schedule

$$
V^{\dagger}(\theta, \bar{u})=\left\{\begin{array}{cl}
\frac{1}{2}(\theta-(1-\sqrt{2 \bar{u}}))^{2} & \text { if } \theta \geq 1-\sqrt{2 \bar{u}} \\
0 & \text { if } \theta<1-\sqrt{2 \bar{u}}
\end{array},\right.
$$

with domain on $[0,1] \times\left[\frac{2}{9}, \frac{1}{2}\right)$. Moreover, the distribution over indirect utilities left to the highest type, denoted by $F^{\dagger}(\bar{u} ; 1)$, solves the following equation in $y$ :

$$
\frac{\Lambda(y)}{\Lambda(0)}=\frac{\frac{2}{27}}{\bar{u}(1-\sqrt{2 \bar{u}})} .
$$

The support of $F^{\dagger}(\bar{u} ; 1)$ is $\left[\frac{2}{9}, \overline{\bar{u}}\right]$, where $\overline{\bar{u}}$ uniquely solves $F^{\dagger}(\overline{\bar{u}} ; 1)=1$.

Proposition 2 is useful for comparing equilibria under laissez-faire and linear pricing. Before doing so, it is instructive to describe the relevant "indirect implementation" where firms post linear tariffs.

Corollary 3 [Equilibrium: Indirect Implementation] The equilibrium $\mathbf{F}^{\dagger}$ from Proposition 1 can be indirectly implemented by firms randomizing over the linear tariffs

$$
T^{\dagger}(q ; \bar{u})=q(1-\sqrt{2 \bar{u}})
$$

where $\bar{u}$ is distributed according to $F^{\dagger}(\bar{u} ; 1)$.

Firms in equilibrium randomize over constant per-unit prices, or, equivalently, over linear tariffs. As in the previous section, we find it convenient to index firms' offers by the indirect utility left to consumers with the highest type, which is $\bar{u}$. Figure 4 , in its left-side panel, illustrates the linear tariff schedules associated with different degrees of generosity.

To understand the equilibrium distortions (relative to the efficiency), it useful to consider, for each offer $\bar{u}$, the quantity schedule $q^{\dagger}(\theta, \bar{u})$, which describes the quantity purchased by type $\theta$ if the offer $\bar{u}$ is the best one observed. Employing incentive compatibility, we can derive $q^{\dagger}(\theta, \bar{u})$ as

$$
q^{\dagger}(\theta, \bar{u})=V_{1}^{\dagger}(\theta, \bar{u})=\max \{\theta-(1-\sqrt{2 \bar{u}}), 0\} .
$$

Notice that $q^{\dagger}(\theta, \bar{u})>0$ if and only if $\theta>1-\sqrt{2 \bar{u}}$. As in the previous section, the interval $(1-\sqrt{2 \bar{u}}, 1]$ is the service range of offer $\bar{u}$.

All types outside of this range purchase nothing from the firm. More generous offers serve a larger range of consumer types and induce each served type to purchase a higher quantity. Again, not all offers in the range $\bar{u} \in\left[\frac{2}{9}, \frac{1}{2}\right]$ are posted in equilibrium: ${ }^{18}$ namely, only those satisfying $\bar{u} \in\left[\frac{2}{9}, \overline{\bar{u}}\right]$, where $\overline{\bar{u}}$ in the upper limit of the support of $F^{\dagger}(\bar{u} ; 1)$.

Note that, whenever type $\theta$ is served under the offer $\bar{u} \in\left[\frac{2}{9}, \frac{1}{2}\right)$ (that is, $q^{\dagger}(\theta, \bar{u})>0$ ), the quantity purchased is strictly below its efficient level: $q^{\dagger}(\theta, \bar{u})<q^{e}(\theta)=\theta$ for all $\theta$, including at the top. This

\footnotetext{
${ }^{18} \mathrm{As}$ in Section 3, the menu $\bar{u}=\frac{1}{2}$ is the perfectly competitive (or Bertrand) offer, which charges a zero price per quantity. It obviously constitutes an upper bound on firms' generosity.
} 

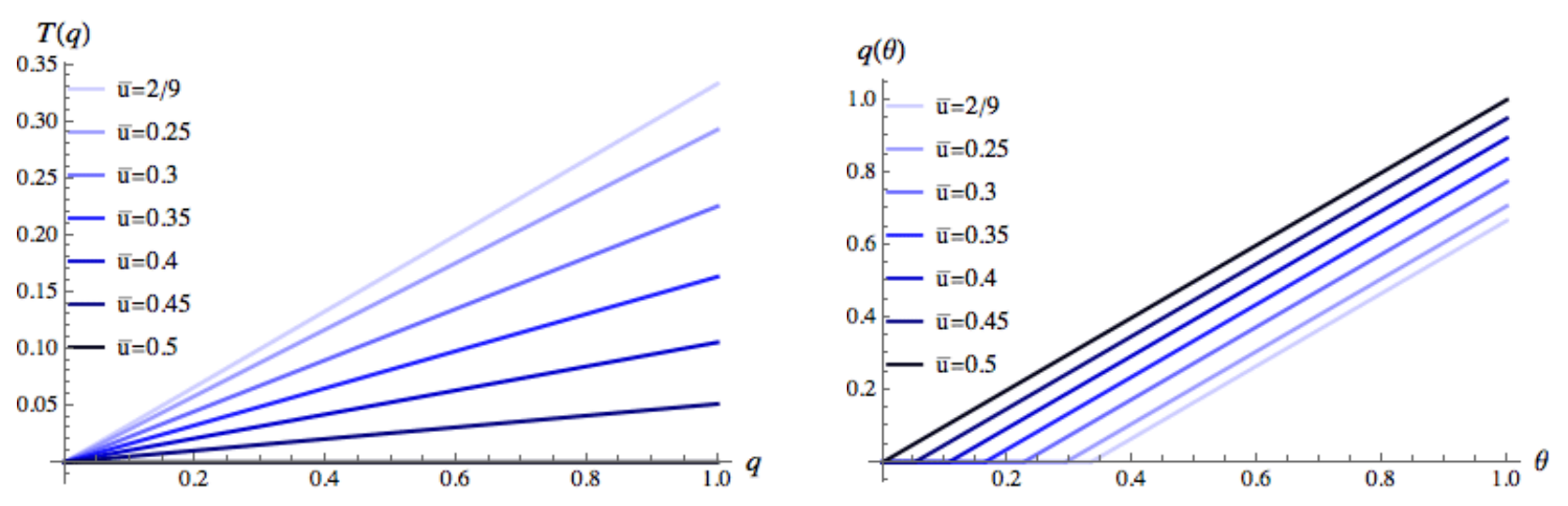

Figure 4: The linear tariff schedules (left-side panel) and quantity schedules (right-side panel) associated with different degrees of generosity.

is unlike the laissez-faire equilibrium, which exhibits efficiency at the top in all equilibrium menus. These quantity (downward) distortions decrease (in magnitude) as the offer under consideration becomes more generous, in that

$$
q^{e}(\theta)-q^{\dagger}(\theta, \bar{u})=1-\sqrt{2 \bar{u}}
$$

is decreasing in $\bar{u}$. Moreover, for a fixed $\bar{u}$, distortions are invariant to consumer types (while decreasing in $\theta$ in the laissez-faire equilibrium). Figure 4 (right-side panel) illustrates the quantity schedules $q^{\dagger}(\theta, \bar{u})$ for different generosities.

We can similarly specialize the characterization of Proposition 2 to obtain the distribution over generosity that describes firms' mixed strategies in equilibrium. For brevity, we only do so for the Poisson case (the cases of Examples 2 and 3 are analogous).

Example 5 [Poisson] Consider the Poisson case from Example 1. Employing Proposition 2, we obtain that distribution over firms' generosity is given by

$$
F^{\dagger}(\bar{u} ; 1)=\frac{1}{\lambda} \ln \left(\frac{\frac{2}{27}}{\bar{u}(1-\sqrt{2 \bar{u}})}\right),
$$

with support over $\left[\frac{2}{9}, \overline{\bar{u}}\right]$, where $\overline{\bar{u}}$ satisfies $e^{-\lambda}=\frac{27}{2} \overline{\bar{u}}(1-\sqrt{2 \overline{\bar{u}}})$. Clearly, as $\lambda$ increases, the cdf $F^{\dagger}(\bar{u} ; 1)$ shifts according to first-order stochastic dominance. Accordingly, firms are more likely to offer more generous menus. By the ordered property of the equilibrium, it then follows that the expected consumer surplus increases in $\lambda$ (for all types served by some equilibrium menu).

The next corollary confirms that comparative statics analogous to those of Corollary 2 hold true in the linear pricing equilibrium.

Corollary 4 [Comparative Statics] Suppose the degree of market transparency increases. Then: 
(a) Firms offer lower per-unit prices (or, equivalently, more generous offers), in that the distribution of generosity $F^{\dagger}(\bar{u} ; 1)$ increases in the sense of first-order stochastic dominance.

(b) The range of types served in equilibrium expands.

(c) The expected consumer surplus increases for all types, strictly so for those served by some equilibrium menu.

Having derived equilibria under laissez-faire (no restrictions on firms' tariffs) and linear pricing, we are now in a position to compare these two scenarios regarding its effects on consumer surplus, firms' profits and welfare.

\section{On the Welfare Effects of Price Discrimination}

The imposition of linear pricing, by definition, affects the shape of firms' tariffs, but it also affects the incentives faced by firms to compete for consumers (i.e., the distribution of offers).

To analyze the former effect, let us fix the generosity of an offer $\bar{u}$, identified to be the indirect utility of the highest type. The equilibrium tariffs under laissez-faire and linear pricing are then such that, for all $\bar{u} \in\left(\frac{1}{4}, \frac{1}{2}\right)$,

$$
T^{*}(q ; \bar{u}) \geq T^{\dagger}(q ; \bar{u}) \quad \text { if and only if } \quad q \leq \frac{2(\sqrt{2 \bar{u}}-2 \bar{u})}{1-2 \bar{u}} \in(0,1) .
$$

Accordingly, holding $\bar{u}$ fixed, the laissez-faire tariff is higher than its linear counterpart except for very high quantities (purchased by the highest types). This is due to the fact that price discrimination takes the form of quantity discounts in the laissez-faire equilibrium.

This observation suggests that linear pricing should indeed benefit low types. This conclusion is unwarranted, however, unless one takes account how linear pricing affects the distribution of offers (i.e., the cdf over $\bar{u}$ 's) practiced by firms under each scenario. Our next result does precisely this, building on Propositions 1 and 2 .

Proposition 3 [Redistributive Effects of Linear Pricing] There exist $\underline{\theta}$ and $\bar{\theta}$ satisfying $0<\underline{\theta}<\bar{\theta}<1$ such that,

(a) For all $\theta<\underline{\theta}$, the distribution $F^{\dagger}(\tilde{u} ; \theta)$ first-order stochastically dominates $F^{*}(\tilde{u} ; \theta), 19$

(b) For all $\theta>\bar{\theta}$, the distribution $F^{*}(\tilde{u} ; \theta)$ first-order stochastically dominates $F^{\dagger}(\tilde{u} ; \theta)$.

\footnotetext{
${ }^{19}$ Strictly so for $\theta$ close to $\underline{\theta}$. If $\theta$ is close to zero, the consumer is excluded under both pricing regimes, so the statement is trivially true.
} 


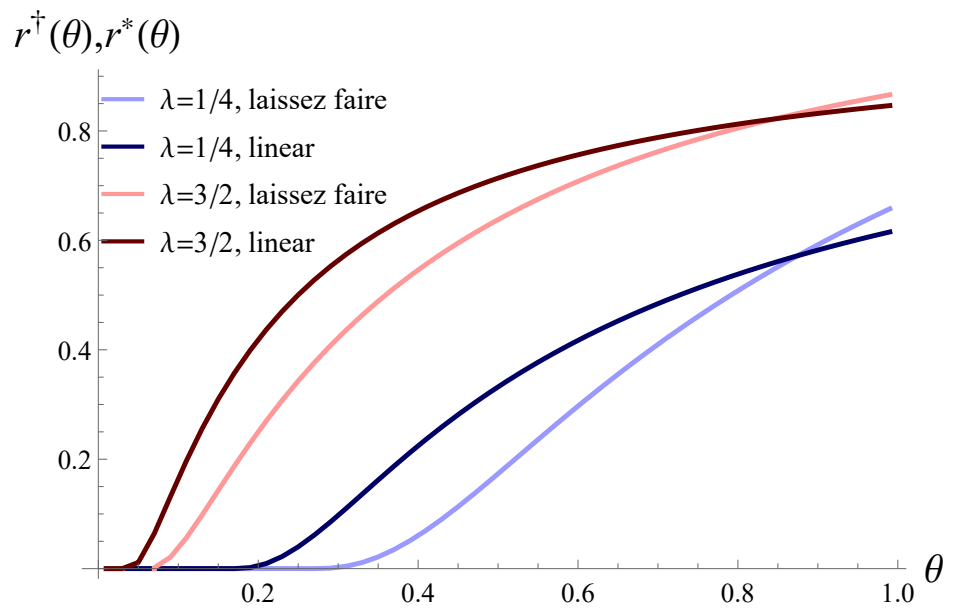

Figure 5: The schedules $r^{*}(\theta)$ and $r^{\dagger}(\theta)$ for different degrees of market transparency under the Poisson parametrization.

Intuitively, the inability to price discriminate pushes firms to compete less intensively for hightype consumers, which leads to (probabilistically) lower payoffs. Being unable to extract too much rents from high types, firms under linear pricing compete more fiercely for low types. Although menus are (probabilistically) less generous, the imposition of linear pricing ends up benefiting these consumers.

To get a quantitative sense of Proposition 3, let us define the ex-ante consumer surplus of type $\theta$ under linear pricing according to

$$
C S^{\dagger}(\theta) \equiv \sum_{s=1}^{N} \omega_{s}\left(\int_{\frac{1}{4}}^{\overline{\bar{u}}} V^{\dagger}(\theta, \bar{u}) d\left(F^{\dagger}(\bar{u} ; 1)\right)^{s}\right)
$$

This definition is analogous to that under laissez-faire. We can similarly define the ratio

$$
r^{\dagger}(\theta) \equiv \frac{C S^{\dagger}(\theta)}{C S^{e}(\theta)}
$$

which describes the fraction of their Bertrand-pricing payoff appropriated by consumers under imperfect competition and linear pricing. Figure 5 compares the ratios $r^{*}(\theta)$ and $r^{\dagger}(\theta)$ in the Poisson specification of Example 1, for various degrees of market transparency. The redistributive effect of imposing linear pricing is notable: Low types now appropriate a much larger fraction of the efficient surplus, while high types lose from this regulation.

We now turn to evaluate the net effect on average consumer surplus, which aggregates the indirect utility across all types. Namely, we compare the quantities

$$
\mathbb{E}\left[C S^{*}(\theta)\right]=\int_{0}^{1} C S^{*}(\theta) d \theta \quad \text { and } \quad \mathbb{E}\left[C S^{\dagger}(\theta)\right]=\int_{0}^{1} C S^{\dagger}(\theta) d \theta
$$




\section{consumer surplus}

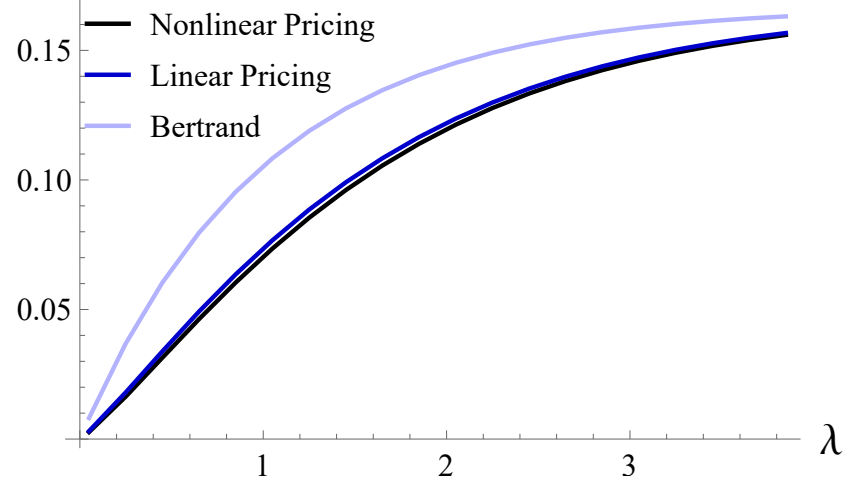

Figure 6: Average consumer surplus under Bertrand pricing, laissez-faire and linear pricing for different degrees of market transparency under the Poisson parametrization.

for different degrees of market transparency. For intuition, recall that, in the Poisson specification of Example 1, the parameter $\lambda$ stands for the average number of offers observed by consumers. Figure 6 illustrates the comparison.

As direct inspection reveals, relative to laissez-faire, consumer surplus is always higher in the linear pricing equilibrium. The effect is however very modest, as a slight increase in the number of offers observed by consumers (under laissez-faire) makes up for the gain in consumer surplus produced by linear pricing. This result accords with the renewed interest by regulators in policies promoting market transparency (see Footnote 6). While improving aggregate consumer surplus, pro-transparency policies have limited distributive effects: As illustrated in Figure 3, improvements in market transparency benefit disproportionately more consumers whose willingness to pay is high, rather than low.

Let us now consider firms' profits. As firms are indifferent between all equilibrium menus, and the monopolistic menu is always part of the equilibrium support, it immediately follows that

$$
\Pi^{\dagger}=\frac{2}{27} \nu \omega_{1} \leq \frac{1}{12} \nu \omega_{1}=\Pi^{*},
$$

where, recall, $\omega_{1}$ is the probability that a consumer observes a single firm. Accordingly, relative to laissez-faire, the imposition of linear pricing decreases firms' profits by approximately $11 \%$ (for any distribution over the size of consumers' consideration sets).

Finally, we assess quantitively the effect of imposing linear pricing on social welfare (that sums the average consumer surplus to firms' profits). As illustrated by Figure 7 for the Poisson specification, social welfare slightly decreases, for any degree of market transparency. The same conclusion obtains for the other specifications under consideration (Binomial and Geometric).

All in all, although slightly decreasing utilitarian welfare, and more substantially decreasing firms' profits, the imposition linear pricing generates substantial distributive benefits. This accords with 


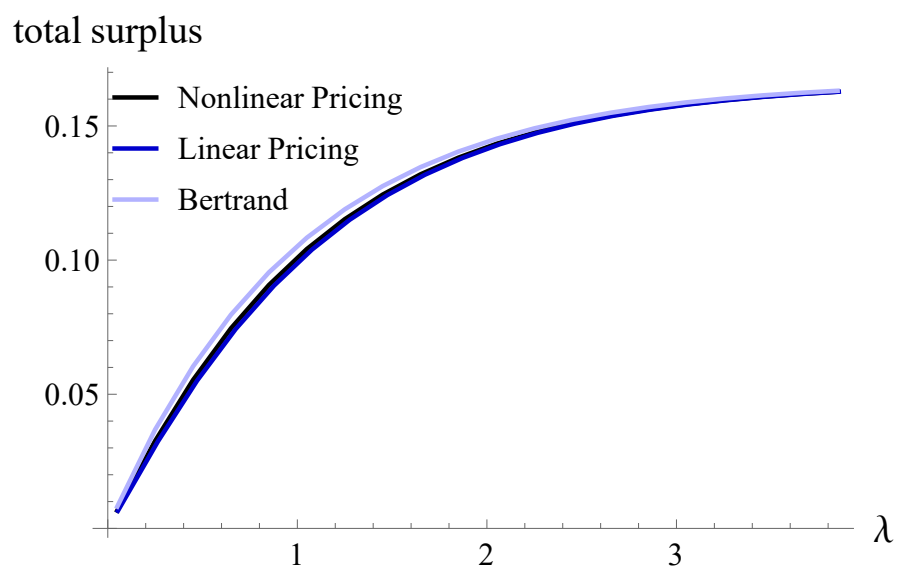

Figure 7: Social welfare under Bertrand pricing, laissez-faire and linear pricing for different degrees of market transparency under the Poisson parametrization.

the use of social tariffs in electricity/gas regulation, where distributive concerns play an important role in the policy debate.

\section{Discussion and Conclusion}

This paper proposes a model of oligopolistic competition under asymmetric information about consumer tastes. Firms' market power originates from consumers' heterogeneous information about market offers. We compare equilibrium outcomes under laissez-faire and linear pricing.

As all firms offer quantity discounts in the laissez-faire equilibrium, imperfect competition benefits disproportionately more consumers whose willingness to pay is high, rather than low. Linearpricing regulation is an effective tool to address distributive concerns, as it substantially raises the payoffs of consumers with low willingness to pay, while hurting (but not too much) those with high willingness to pay. Perhaps surprisingly, average consumer surplus increases. However, the imposition of linear pricing adversely affects firms' profits, enough to drive down utilitarian welfare.

We contrast imposing linear pricing with policies that promote market transparency (whereby consumer observe and compare a larger sample of firms). The latter increase utilitarian welfare, and achieve similar gains on consumer surplus as linear pricing, although with limited distributive impact. On normative grounds, our analysis suggests that banning price discrimination is warranted only if its distributive benefits are part of the societal objective.

For tractability, our analysis proceeded under some stark assumptions that could be relaxed in future work. A case in point is the statistical independence between the size of consumers' consideration sets and their preferences for the good. In electricity markets, for instance, consumers with low income (low-usage) are found to consider fewer options at the time of selecting a utility 
company than those with high-income (see Byrne, Martin and Nah 2019). Relatedly, in the context of the market for residential natural gas in the UK, Giulietti, Waddams Price and Waterson (2005) find that consumer's awareness about competing offers substantially varies with household characteristics (e.g., older consumers have smaller consideration sets). In light of these findings, we expect that policies that promote market transparency among the least informed consumers (e.g., the poor and the old) exhibit greater distributive impact than the one analyzed in this paper (which applies uniformly across consumers).

Another important simplifying assumption pertains to the price setting mechanism prevalent in the market. While this paper assumes that firms can commit to tariffs, some recent empirical contributions document widespread bargaining among consumers and utility providers. For instance, Byrne, Martin and Nah (2019) show that electricity providers in Australia use price posting and negotiation to price discriminate according to consumers' willingness or ability to search and haggle ${ }^{20}$ This phenomenon finds echo in the recent theoretical contribution of Fabra and Reguant (2020), who propose a model where firms observe information about buyers' willingness to search before making an offer. Relatedly, Armstrong and Vickers (2019) allow firms to discriminate against captive consumers (who observe no other offer), and assess the welfare impact of banning such practice. It would be an interesting avenue for future research to study the distributive effects of search-based discrimination when consumers enjoy private information about their preferences (as assumed here).

Finally, future work could analyze how tariff regulation affects the entry of firms in the market. This paper points to the following trade-off: While advancing equity among consumers (holding the number of competitors fixed), linear-pricing regulation substantially reduces firms' profits. This is likely to decrease the number of active firms in the market, thus weakening competition, with adverse effects on the very consumers regulation aimed at benefiting.

\footnotetext{
${ }^{20}$ A related contribution is that of Allen, Clark and Houde (2019), who, in the context of the Canadian mortgage market, employ structural techniques to show that search/bargaining frictions account for a third of firms' market power.
} 


\section{Appendix: Proofs}

Proof of Proposition 1. This result can be found in the supplementary material of Garrett, Gomes and Maestri (2019). We reproduce the main steps here to facilitate exposition. Recall that each firm maximizes (2). We construct an equilibrium in which firms are indifferent between every menu from the support $\mathbb{S}$. Each schedule $\theta \rightarrow u(\theta)$ in $\mathbb{S}$ will be strictly increasing, differentiable and weakly convex. Moreover, since menus are ordered, we will parametrize them by the indirect utility $\bar{u}$ they yield to the highest type $\bar{\theta}$. The set $\mathbb{S}$ can thus be written as

$$
\mathbb{S}:=\left\{(V(\theta, \bar{u}))_{\theta \in[0,1]}, \bar{u} \in\left[\bar{u}^{m}, \overline{\bar{u}}\right]\right\}
$$

where $\overline{\bar{u}} \in\left(\bar{u}^{m}, S^{*}(\bar{\theta})\right)$, with $\bar{u}^{m}$ standing for the utility of type $\bar{\theta}$ in the Mussa-Rosen Menu, $S^{*}(\bar{\theta})$ standing for the utility of type $\bar{\theta}$ in the Bertrand Menu and $\overline{\bar{u}}$ being a variable determined below. Since menus are ordered, we must have

$$
\Lambda(F((V(\theta, \bar{u})) ; \theta))=\Lambda(F((V(\bar{\theta}, \bar{u})) ; \bar{\theta}))
$$

for every $\theta$ for which $V(\theta, \bar{u})>0$. This implies

$$
\frac{d}{d \theta} \Lambda(F((V(\theta, \bar{u})) ; \theta))=0
$$

for every $\theta$ for which $V(\theta, \bar{u})>0$. Moreover, notice that by construction $V(\bar{\theta}, \bar{u})=\bar{u}$. Therefore we have

$$
\Lambda^{\prime}(F((V(\theta, \bar{u})) ; \theta)) f(V(\theta, \bar{u}) ; \theta) V_{2}(\theta, \bar{u})=\Lambda^{\prime}(F(\bar{u} ; \bar{\theta})) f(V(\bar{\theta}, \bar{u}) ; \theta)
$$

We will construct in equilibrium which is smooth in the following sense: Take any $(V(\theta, \bar{u}))_{\theta \in[0,1]} \in$ $\mathbb{S}$ with $\bar{u} \in\left(\bar{u}^{m}, \overline{\bar{u}}\right)$. For any $\theta$ for which $V(\theta, \bar{u})>0$, there exists a neighborhood $\mathcal{N}$ of $(\theta, \bar{u})$ at which $(\tilde{\theta}, \widetilde{\bar{u}}) \rightarrow V(\tilde{\theta}, \widetilde{\bar{u}})$ is smooth. This and the optimality of the menu $(V(\theta, \bar{u}))_{\theta \in[0,1]}$ imply that the following Euler equation is necessary for the firm's optimality:

$$
\begin{gathered}
\Lambda^{\prime}(F((V(\theta, \bar{u})) ; \theta)) f(V(\theta, \bar{u}) ; \theta)\left(\theta V_{1}(\theta, \bar{u})-\varphi\left(V_{1}(\theta, \bar{u})\right)\right)-V(\theta, \bar{u})-\Lambda(F((V(\theta, \bar{u})) ; \theta)) \\
\frac{d}{d \theta}\left\{\Lambda(F((V(\theta, \bar{u})) ; \theta))\left(\theta-\varphi^{\prime}\left(V_{1}(\theta, \bar{u})\right)\right)\right\} .
\end{gathered}
$$

Because of (9), it follows that

$$
\begin{aligned}
& \frac{d}{d \theta}\left\{\Lambda(F((V(\theta, \bar{u})) ; \theta))\left(\theta-\varphi^{\prime}\left(V_{1}(\theta, \bar{u})\right)\right)\right\} \\
= & \Lambda(F((V(\theta, \bar{u})) ; \theta)) \frac{d}{d \theta}\left\{\theta-\varphi^{\prime}\left(V_{1}(\theta, \bar{u})\right)\right\}
\end{aligned}
$$

Using equations 11], 12 and straightforward algebra we get

$$
\frac{\Lambda^{\prime}(F(V(\theta, \bar{u}) ; \theta))}{\Lambda(F(V(\theta, \bar{u}) ; \theta))} f(V(\theta, \bar{u}) ; \theta)=\frac{1+\frac{d}{d \theta}\left\{\left(\theta-\varphi^{\prime}\left(V_{1}(\theta, \bar{u})\right)\right)\right\}}{\left(\theta V_{1}(\theta, \bar{u})-\varphi\left(V_{1}(\theta, \bar{u})\right)-V(\theta, \bar{u})\right)} .
$$


If we choose $\theta=\bar{\theta}$ in 13 to obtain that:

$$
\frac{\Lambda^{\prime}(F(\bar{u} ; \bar{\theta}))}{\Lambda(F(\bar{u} ; \bar{\theta}))} f(\bar{u} ; \bar{\theta})=\frac{1+\frac{d}{d \theta}\left\{\left(\theta-\varphi^{\prime}\left(V_{1}(\theta, \bar{u})\right)\right)\right\}_{\theta=\bar{\theta}}}{\left(\bar{\theta} V_{1}(\bar{\theta}, \bar{u})-\varphi\left(V_{1}(\bar{\theta}, \bar{u})\right)-\bar{u}\right)} .
$$

Using (10) we obtain

$$
\left(\frac{\Lambda^{\prime}(F(V(\theta, \bar{u}) ; \theta))}{\Lambda(F(V(\theta, \bar{u}) ; \theta))} f(V(\theta, \bar{u}) ; \theta)\right)^{-1} \frac{\Lambda^{\prime}(F(\bar{u} ; \bar{\theta}))}{\Lambda(F(\bar{u} ; \bar{\theta}))} f(V(\theta, \bar{u}) ; \bar{\theta})=V_{2}(\theta, \bar{u}),
$$

Dividing (13) by (14), and using (15), we obtain

$$
V_{2}(\theta, \bar{u})=\frac{\left(\theta V_{1}(\theta, \bar{u})-\varphi\left(V_{1}(\theta, \bar{u})\right)-V(\theta, \bar{u})\right)}{\left(\bar{\theta} V_{1}(\bar{\theta}, \bar{u})-\varphi\left(V_{1}(\bar{\theta}, \bar{u})\right)-V(\bar{\theta}, \bar{u})\right)} \cdot\left(\frac{1+\frac{d}{d \theta}\left\{\left(V_{1}(\theta, \bar{u})-\varphi^{\prime}\left(V_{1}(\theta, \bar{u})\right)\right)\right\}_{\theta=\bar{\theta}}}{1+\frac{d}{d \theta}\left\{\left(V_{1}(\theta, \bar{u})-\varphi^{\prime}\left(V_{1}(\theta, \bar{u})\right)\right)\right\}}\right) .
$$

In the constructed equilibrium, the highest type $\bar{\theta}$ is always assigned the efficient quality level. In this case, the PDE above becomes

$$
V_{2}(\theta, \bar{u})=\frac{\left(\theta V_{1}(\theta, \bar{u})-\varphi\left(V_{1}(\theta, \bar{u})\right)-V(\theta, \bar{u})\right)}{\left(S^{*}(\bar{\theta})-\bar{u}\right)} \cdot\left(\frac{1+\frac{d}{d \theta}\left\{\left(V_{1}(\theta, \bar{u})-\varphi^{\prime}\left(V_{1}(\theta, \bar{u})\right)\right)\right\}_{\theta=\bar{\theta}}}{1+\frac{d}{d \theta}\left\{\left(V_{1}(\theta, \bar{u})-\varphi^{\prime}\left(V_{1}(\theta, \bar{u})\right)\right)\right\}}\right) .
$$

The PDE 16 has to be solved in the range $\bar{u} \in\left[\bar{u}^{m}, S^{*}(\bar{\theta})\right], \theta \in[\underline{\theta}, \bar{\theta}]$ with boundary conditions

$$
\begin{gathered}
V\left(\theta, S^{*}(\theta)\right)=\max _{q} \theta q-\varphi(q) \\
V\left(\theta, \bar{u}^{m}\right)=\max _{q}\left(\theta-\frac{1-\theta}{\theta}\right) q-\varphi(q) \\
V_{1}(\bar{\theta}, \bar{u})=V_{1}\left(\bar{\theta}, S^{*}(\bar{\theta})\right)
\end{gathered}
$$

and

$$
V(\bar{\theta}, \bar{u})=\bar{u} .
$$

The boundary condition (17) insists that the Bertrand schedule is a supremum over all contracts. We remark that, for any degree of market transparency, this schedule will not be offered. However, the most generous schedule will approach that schedule as transparency becomes more and more intense. Condition (18) insists that the least generous schedule in $\mathbb{S}$ is given by the Mussa-Rosen schedule. Condition 19 insists that a surplus-maximizing quality is always offered to type $\bar{\theta}$. Finally, 20 is a consistency condition.

After using our quadratic-cost assumption, $\varphi(q)=\frac{1}{2} q^{2}$, the PDE 16 becomes

$$
V_{2}(\theta, \bar{u})=\left(\frac{2-V_{11}(\bar{\theta}, \bar{u})}{2-V_{11}(\theta, \bar{u})}\right)\left(\frac{\theta V_{1}(\theta, \bar{u})-\frac{1}{2}\left(V_{1}(\theta, \bar{u})\right)^{2}-V(\theta, \bar{u})}{\frac{1}{2}-\bar{u}}\right)
$$

with domain on $[0,1] \times\left[\frac{1}{4}, \frac{1}{2}\right]$. 
The following function solves the PDE (21) subject to the boundary conditions (17)-20):

$$
V(\theta, u)=\frac{\theta^{2}}{4 u}+\left(1-\frac{1}{2 u}\right) \theta+u+\frac{1}{4 u}-1
$$

To construct an equilibrium we must construct the support $\mathbb{S}:=\left\{(V(\theta, \bar{u}))_{\theta \in[0,1]}, \bar{u} \in\left[\bar{u}^{m}, \overline{\bar{u}}\right]\right\}$ as well as the randomization over schedules $F^{*}(\bar{u} ; 1)$. First, to find the most generous schedule $(V(\theta, \overline{\bar{u}}))_{\theta \in[0,1]}$ we use the following isoprofit condition

$$
\frac{\Lambda(1)}{\Lambda(0)}=\frac{\frac{1}{48}}{\int_{0}^{1}\left(\theta V_{1}(\theta, \overline{\bar{u}})-V(\theta, \overline{\bar{u}})-\frac{1}{2}\left[V_{1}(\theta, \overline{\bar{u}})\right]^{2}\right) d \theta} .
$$

Similarly, we calculate the distribution over the support $\mathbb{S}$. For that we use the isoprofit condition to obtain the quantile $F^{*}(\bar{u} ; 1)$ of menu $(V(\theta, \bar{u}))_{\theta \in[0,1]}$ for $\bar{u} \in\left[\bar{u}^{m}, \overline{\bar{u}}\right]$ :

$$
\frac{\Lambda\left(F^{*}(\bar{u} ; 1)\right)}{\Lambda(0)}=\frac{\frac{1}{48}}{\int_{0}^{1}\left(\theta V_{1}(\theta, \bar{u})-V(\theta, \bar{u})-\frac{1}{2}\left[V_{1}(\theta, \bar{u})\right]^{2}\right) d \theta}=\frac{1}{8 \bar{u}(1-2 \bar{u})},
$$

where the second equality uses straightforward algebra. Finally, we must guarantee the optimality of all schedules $(V(\theta, \bar{u}))_{\theta \in[0,1]} \in \mathbb{S}$. We remark that by construction all schedules $(V(\theta, \bar{u}))_{\theta \in[0,1]} \in \mathbb{S}$ yield the same profit and solve the Euler equation (11). Garrett, Gomes and Maestri (2019) verify that this calculus-of-variation necessary condition is also sufficient for optimality. This completes the equilibrium construction.

Proof of Corollary 1. We must show that type $\theta$ chooses

$$
\begin{gathered}
q(\theta, \bar{u}):=V_{1}(\theta, \bar{u}) \\
=\frac{\partial}{\partial \theta}\left[\frac{\theta^{2}}{4 \bar{u}}+\left(1-\frac{1}{2 \bar{u}}\right) \theta+\bar{u}+\frac{1}{4 \bar{u}}-1\right] \\
=\frac{2 \theta}{4 \bar{u}}+\left(1-\frac{1}{2 \bar{u}}\right) .
\end{gathered}
$$

Given the schedule $T(q ; \bar{u})=\left(\bar{u}-\frac{1}{2}\right) q^{2}+q(1-2 \bar{u})$, it is immediate to verify that any type $\theta \leq 1-2 \bar{u}$ chooses $q=0$, while type $\theta>1-2 \bar{u}$ chooses

$$
q(\theta ; T(q ; \bar{u})):=\arg \max _{q}\left\{\theta q-\frac{q^{2}}{2}-\left[\left(\bar{u}-\frac{1}{2}\right) q^{2}+q(1-2 \bar{u})\right]\right\}
$$

Since this problem is strictly concave, the solution is given by the first-order condition, which delivers

$$
q(\theta ; T(q ; \bar{u}))=\frac{2 \theta}{4 \bar{u}}+\left(1-\frac{1}{2 \bar{u}}\right) .
$$

Proof of Corollary 2, We first prove 1. Recall that the degree of transparency is higher under $\Lambda$ than under $\hat{\Lambda}$ if $\frac{\Lambda(y)}{\Lambda(0)}>\frac{\hat{\Lambda}(y)}{\hat{\Lambda}(0)}$ for all $y \in(0,1]$. Let $y(\bar{u})$ be the quantile of the equilibrium menu 
$(V(\theta, \bar{u}))_{\theta \in[0,1]}$ under $\Lambda$ and $\hat{y}(\hat{u})$ be the one of the equilibrium menu $(\hat{V}(\theta, \hat{u}))_{\theta \in[0,1]}$ under $\hat{\Lambda}$. Take $z \in(0,1), \bar{u}$ and $\hat{u}$ such that $y(\bar{u})=\hat{y}(\hat{u})=z$. We have

$$
\frac{\Lambda(y(\bar{u}))}{\Lambda(0)}=\frac{1}{8 \bar{u}(1-2 \bar{u})} \quad \text { and } \quad \frac{\hat{\Lambda}(\hat{y}(\hat{u}))}{\hat{\Lambda}(0)}=\frac{1}{8 \hat{u}(1-2 \hat{u})} .
$$

Hence $\frac{\Lambda(y(\bar{u}))}{\Lambda(0)}>\frac{\hat{\Lambda}(\hat{y}(\hat{u}))}{\hat{\Lambda}(0)}$ implies $8 \hat{u}(1-2 \hat{u})>8 \bar{u}(1-2 \bar{u})$. Since $x \rightarrow 8 x(1-2 x)$ is strictly decreasing over the domain $\left[\frac{1}{4}, \frac{1}{2}\right)$, this implies $\bar{u}>\hat{u}$, which proves the claim.

To prove 2 ., let $\bar{u}, \hat{u}$ satisfy

$$
\frac{\Lambda(1)}{\Lambda(0)}=\frac{1}{8 \bar{u}(1-2 \bar{u})} \quad \text { and } \quad \frac{\hat{\Lambda}(1)}{\hat{\Lambda}(0)}=\frac{1}{8 \hat{u}(1-2 \hat{u})} .
$$

Again, since $x \rightarrow 8 x(1-2 x)$ is strictly decreasing over the domain $\left[\frac{1}{4}, \frac{1}{2}\right)$, we have $\bar{u}>\hat{u}$, and hence $1-2 \bar{u}<1-2 \hat{u}$. Since the range of types in equilibrium under $\Lambda$ is $[1-2 \bar{u}, 1]$ and under $\hat{\Lambda}$ is $[1-2 \hat{u}, 1]$ the claim follows.

To prove 3., take $(\theta, \bar{u})$ such that $V(\theta, \bar{u})>0$. Recall that $V(\theta, \bar{u})=\frac{\theta^{2}}{4 \bar{u}}+\left(1-\frac{1}{2 \bar{u}}\right) \theta+\bar{u}+\frac{1}{4 \bar{u}}-1$ and hence

$$
\frac{\partial V(\theta, \bar{u})}{\partial \bar{u}}=-\frac{(1-\theta)^{2}}{4 \bar{u}^{2}}+1
$$

Since $V(\theta, \bar{u})>0$ implies $\theta>1-2 \bar{u}$, we have $(1-\theta)^{2}<4 \bar{u}^{2}$, and hence $-\frac{(1-\theta)^{2}}{4 \bar{u}^{2}}+1>0$, implying $\frac{\partial V(\theta, \bar{u})}{\partial \bar{u}}>0$. This and 1. imply the claim.

Proof of Proposition 2, Let $\mathbb{P}$ be the set of equilibrium prices and let $\mathbf{F}^{p}$ be its distribution. Let $\underline{p}$ be the infimum of $\mathbf{F}^{p}$ and $\bar{p}$ be its supremum.

Recall that $p=\frac{1}{3}$ is the monopoly price. Let $y(p)=\mathbf{F}^{p}(p)$ be the quantile relative to price $p$. The profit is given by:

$$
\Lambda(y(p)) \int_{0}^{1} \max \{\theta-p, 0\} p d \theta .
$$

Observe also that if $\mathbf{F}^{p}$ has a mass point at some $\tilde{p}$ then the sale from this price is

$$
\lim _{\varepsilon \downarrow 0} \frac{\Lambda\left(F^{*}(p-\varepsilon)\right)+\Lambda\left(F^{*}(p+\varepsilon)\right)}{2}<\Lambda\left(F^{*}(p-\nu)\right)
$$

for any $\nu>0$.

Notice that since $\Lambda(0)>0$, a lower bound to the firm's profit is given by

$$
\Lambda(0) \int_{0}^{1} \max \left\{\theta-\frac{1}{3}, 0\right\} \frac{1}{3} d \theta=\frac{2}{27} \Lambda(0)>0 .
$$

Finally, we let $\mathbb{U}$ be the support of the distribution of utilities of type $\bar{\theta}$.

\section{Step 1. The distribution $\mathrm{F}^{p}$ has no mass points.}

Assume towards a contradiction that $\mathbf{F}^{p}$ has a mass point at some price $\tilde{p}$. Then the last inequality and (22) imply that the firm can profitably deviate by setting $\tilde{p}-\eta$ for some small $\eta$. 


\section{Step 2. The supremum of $\mathbb{P}$ is $\frac{1}{3}$.}

Clearly, the supremum of $\mathbb{P}$ cannot be above $\frac{1}{3}$ as otherwise the firm would increase its profits and attract a larger set of consumers by setting $p=\frac{1}{3}$. Hence assume towards a contradiction that the supremum of $\mathbb{P}$ is $\bar{p}<\frac{1}{3}$. By Step $1, \bar{p}$ is optimal, yielding

$$
\Lambda(0) \int_{0}^{1} \max \{\theta-\bar{p}, 0\} \bar{p} d \theta<\frac{2}{27} \Lambda(0),
$$

contradicting (23).

Step 3. The support of $\mathbb{P}$ is an interval.

Suppose towards a contradiction that there exists a (without loss) maximal interval $\left(p_{1}, p_{2}\right) \notin$ $\mathbb{P}$. Step 1 implies that $\mathbf{F}^{p}\left(p_{1}\right)=\mathbf{F}^{p}\left(p_{2}\right)$. This and the optimality of $p_{1}$ and $p_{2}$ imply

$$
\int_{0}^{1} \max \left\{\theta-p_{1}, 0\right\} p_{1} d \theta=\int_{0}^{1} \max \left\{\theta-p_{2}, 0\right\} p_{2} d \theta,
$$

which is a contradiction as $p \rightarrow \int_{0}^{1} \max \{\theta-p, 0\} p d \theta$ is strictly increasing in the interval $\left(0, \frac{1}{3}\right)$.

Step 4. Conclusion. Using the steps above and the fact that every $p \in \mathbb{P}$ yields the same profit. Therefore we have for every $p \in \mathbb{P}$,

$$
\begin{aligned}
\frac{2}{27} \Lambda(0)= & \Lambda\left(\mathbf{F}^{*}(p)\right) \int_{0}^{1} \max \{\theta-p, 0\} p d \theta \\
& =\Lambda\left(\mathbf{F}^{*}(p)\right) \frac{p}{2}(p-1)^{2}
\end{aligned}
$$

Notice next that the utility of type $\theta$ is

$$
\begin{gathered}
u(\theta, p)=\int_{0}^{\max \{\theta-p, 0\}} \max \{\theta-\tilde{q}, 0\} d \tilde{q}-p \max \{\theta-p, 0\} \\
=\frac{(\max \{\theta-p, 0\})^{2}}{2} .
\end{gathered}
$$

Therefore the utility of type $\bar{\theta}$ is given by

$$
\bar{u}=u(1, p)=\int_{0}^{1-p}(1-\tilde{q}) d \tilde{q}-p(1-p)=\frac{(1-p)^{2}}{2} .
$$

Therefore we have $p(\bar{u})=1-\sqrt{2 \bar{u}}$. Using this and $(24)$ we obtain

$$
\frac{2}{27} \Lambda(0)=\Lambda\left(\mathbf{F}^{p}(p)\right) \bar{u}(1-\sqrt{2 \bar{u}})
$$

delivering (7). Recall that by Step 2 the supremum of of $\mathbb{P}$ is $\frac{1}{3}$, which implies that the infimum of $\mathbb{U}$ is $\frac{\left(1-\frac{1}{3}\right)^{2}}{2}=\frac{2}{9}$. On the other hand, the supremum of $\mathbb{U}$ solves

$$
\frac{2}{27} \Lambda(0)=\Lambda(1) \overline{\bar{u}}(1-\sqrt{2 \overline{\bar{u}}})
$$

Next notice that

$$
V(\theta, \bar{u})=u(\theta, p(\bar{u}))=\frac{(\max \{\theta-1+\sqrt{2 \bar{u}}, 0\})^{2}}{2},
$$


delivering (6). This completes the proof.

Proof of Corollary 3. First it is immediate to check that types $\theta \leq(1-\sqrt{2 \bar{u}})$ best reply to the linear tariff $q(1-\sqrt{2 \bar{u}})$ by choosing $q=0$. The equilibrium requires that types $\theta>(1-\sqrt{2 \bar{u}})$ choose

$$
\frac{\partial V(\theta, \bar{u})}{\partial \theta}=\frac{(\theta-1+\sqrt{2 \bar{u}})^{2}}{2}=(\theta-1+\sqrt{2 \bar{u}})
$$

Next notice that

$$
\begin{aligned}
q(\theta ; T(q ; \bar{u})):= & \arg \max _{q}\left\{\theta q-\frac{q^{2}}{2}-q(1-\sqrt{2 \bar{u}})\right\} \\
& =(\theta-1+\sqrt{2 \bar{u}})
\end{aligned}
$$

Proof of Corollary 4. We first prove 1. Observe that the function $x \rightarrow x(1-\sqrt{2 x})$ is strictly decreasing over the domain $\left[\frac{2}{9}, \frac{1}{2}\right)$. Mutatis mutandis, the argument in 1. from Corollary 2 delivers the result.

Now we prove 2. Assume that the level of transparency is greater under $\Lambda$ than under $\hat{\Lambda}$. Let $\bar{u}$ be the supremum utility received by type $\bar{\theta}$ under $\Lambda$ and let $\hat{u}$ be the respective value under $\hat{\Lambda}$. It follows from the argument in 1 . that $\bar{u}>\hat{u}$, implying $1-\sqrt{2 \bar{u}}<1-\sqrt{2 \hat{u}}$. Hence the set of types served under $\Lambda,[1-\sqrt{2 \bar{u}}, 1]$ is larger than the set of types served under $\hat{\Lambda},[1-\sqrt{2 \hat{u}}, 1]$.

Finally we prove 3 . Take $\theta>1-\sqrt{2 \bar{u}}$ and notice that

$$
\frac{\partial V^{\dagger}(\theta, \bar{u})}{\partial \bar{u}}=\frac{\sqrt{2}}{2 \sqrt{\bar{u}}}(\theta+\sqrt{2 \bar{u}}-1)>0 .
$$

Therefore the result follows from 1 .

Proof of Proposition 3. We first prove part 2. Recall that $F^{*}(\cdot ; \bar{\theta})$ yields the cdf over indirect utilities of type $\bar{\theta}$ under nonlinear-pricing competition, while $F^{\dagger}(\cdot ; \bar{\theta})$ yields the one under linearpricing competition. We would like to show that $F^{*}(\cdot ; \bar{\theta})$ F.O.S.D. $F^{\dagger}(\cdot ; \bar{\theta})$. Let $\left[\frac{1}{4}, \bar{u}^{*}\right]$ be the support of $F^{*}(\cdot ; \bar{\theta})$ and $\left[\frac{2}{9}, \bar{u}^{\dagger}\right]$ be the support of $F^{\dagger}(\cdot ; \bar{\theta})$. First notice that the infimum of the support of $F^{*}(\cdot ; \bar{\theta}), \frac{1}{4}$, is greater than the infimum of the support of $F^{\dagger}(\cdot ; \bar{\theta}), \frac{2}{9}$. Next take any $y \in(0,1)$ and define $u^{*}(y)$ obtained from the nonlinear pricing model by

$$
\frac{\Lambda(y)}{\Lambda(0)}=\frac{1}{8 u^{*}(y)\left(1-2 u^{*}(y)\right)}
$$

Analogously, define the $u^{\dagger}(y)$ obtained by the linear pricing model by

$$
\frac{\Lambda(y)}{\Lambda(0)}=\frac{\frac{2}{27}}{u^{\dagger}(y)\left(1-\sqrt{2 u^{\dagger}(y)}\right)} .
$$


Using these two equations and straightforward algebra we obtain

$$
u^{*}(y)=\frac{\frac{1}{2}+\sqrt{\frac{1}{4}-\frac{27}{8} u^{\dagger}(y)\left(1-\sqrt{2 u^{\dagger}(y)}\right)}}{2} .
$$

It is straightforward to verify that the mapping $h(x):=\frac{\frac{1}{2}+\sqrt{\frac{1}{4}-\frac{27}{8} x(1-\sqrt{2 x})}}{2}-x$ takes strictly positive values over the domain $\left[\frac{2}{9}, \frac{1}{2}\right)$, which shows that $u^{*}(y)>u^{\dagger}(y)$ for every $y \in[0,1]$. This implies F.O.S.D. for type $\bar{\theta}$. A straightforward continuity result shows that F.O.S.D. holds for every $\theta \in$ $[\bar{\theta}-\varepsilon, \bar{\theta}]$ for some $\varepsilon>0$.

We now prove part 1 . To prove this part, let $\left[\theta^{*}, 1\right]$ be the set of types served by nonlinear pricing and let $\left[\theta^{\dagger}, 1\right]$ be the set of types served by linear pricing. It suffices to show that $\theta^{\dagger}<\theta^{*}$ as in this case all types $\theta \in\left(\theta^{\dagger}, \theta^{*}\right)$ obtain strictly positive utility with positive probability under linear pricing, obtaining zero with probability one under nonlinear pricing. For that notice that

$$
\theta^{*}=1-2 \bar{u}^{*} \quad \text { and } \quad \theta^{\dagger}=1-\sqrt{2 \bar{u}^{\dagger}}
$$

We must show that $\theta^{\dagger}<\theta^{*}$, which holds if and only if $2 \bar{u}^{*}<\sqrt{2 \bar{u}^{\dagger}}$. In light of (27), we can write this inequality as

$$
2\left(\frac{\frac{1}{2}+\sqrt{\frac{1}{4}-\frac{27}{8} u^{\dagger}(1)\left(1-\sqrt{2 u^{\dagger}(1)}\right)}}{2}\right)<\sqrt{2 u^{\dagger}(1)}
$$

Consider the function $\Psi:\left[\frac{2}{9}, \frac{1}{2}\right)$ given by

$$
\Psi(x):=\frac{1}{2}+\sqrt{\frac{1}{4}-\frac{27}{8} x(1-\sqrt{2 x})}-\sqrt{2 x}
$$

and observe that $\Psi\left(\frac{2}{9}\right)=-\frac{1}{6}<0$. Moreover, it is immediate to verify that $\Psi(x)<0$ for every $x \in\left[\frac{2}{9}, \frac{1}{2}\right)$, which completes the proof. 


\section{References}

[1] Allen, J., R. Clark, and J.-F. Houde, 2019. "Search Frictions and Market Power in NegotiatedPrice Markets." Journal of Political Economy, 127, 1550-1598.

[2] Armstrong, M., and J. Vickers, 2001. "Competitive Price Discrimination." Rand Journal of Economics, 32, 579-605.

[3] Armstrong, M., and J. Vickers, 2019. "Discriminating against Captive Customers." American Economic Review: Insights, 1, 257-72.

[4] Borenstein, S., 2012. "The Redistributional Impact of Nonlinear Electricity Pricing." American Economic Journal: Economic Policy, 4, 56-90.

[5] Byrne, D., L. Martin, and J. Nah, 2019. "Price Discrimination, Search, and Negotiation in an Oligopoly: A Field Experiment in Retail Electricity."

[6] Calzolari, G., and V. Denicolò, 2011. "On the anti-competitive effects of quantity discounts." International Journal of Industrial Organization, 29, 337-341.

[7] Calzolari, G., and V. Denicolò, 2013. "Competition with Exclusive Contracts and Market-Share Discounts." American Economic Review, 103, 2384-2411.

[8] Calzolari, G., and V. Denicolò, 2015. "Exclusive Contracts and Market Dominance." American Economic Review, 105, 3321-3351.

[9] Carlton, D. W., and M. Waldman, 2008. "Safe Harbors for Quantity Discounts and Bundling." George Mason Law Review, 15, 1231-1240.

[10] Crawford, G., and A. Yurukoglu, 2012. "The Welfare Effects of Bundling in Multichannel Television Markets." American Economic Review, 102, 643-685.

[11] Dupuit, J., 1849. "De l'Influence des Péages sur l'Utilité des Voies de Communication", Annales des Ponts et Chaussées, s. II, 1st semester, pp. 170-248; English translation of the last section "On Tolls and Transport Charges", by E. Henderson, International Economic Papers (1962), n. 11, pp. 7-31.

[12] Dworczak, P., S. D. Kominers and M. Akbarpour (2020). "Redistribution through Markets." Working paper.

[13] Ekelund, R. B., 1970. "Price discrimination and product differentiation in economic theory: An early analysis." Quarterly Journal of Economics, 84, 268-278. 
[14] Fabra, N., and M. Reguant, 2020. "A model of search with price discrimination." European Economic Review, 129, 103571.

[15] Feger, F., and D. Radulescu, 2018. "Redistribution through Income Taxation and Public Utility Pricing in the Presence of Energy Efficiency Considerations.” CESifo Working Paper 7195.

[16] Garrett, D., R. Gomes and L. Maestri, 2019. "Competitive Screening under Heterogeneous Information." Review of Economic Studies, 86, 1590-1630.

[17] Giulietti, M., C. Waddams Price and M. Waterson, 2005. "Consumer Choice and Competition Policy: A Study of UK Energy Markets.” Economic Journal, 115, 949-968.

[18] Gomes, R., J.-M. Lozachmeur, and L. Maestri, 2020. "Nonlinear Pricing in Oligopoly: How Brand Preferences Shape Market Outcomes." Working Paper.

[19] Grennan, M., 2013. "Price Discrimination and Bargaining: Empirical Evidence from Medical Devices." American Economic Review, 103, 145-177.

[20] Hagemann, G. P., 2018. "Essays in Nonlinear Pricing." PhD Thesis, University of Texas at Austin.

[21] Jewitt, I., 1991. "Applications of Likelihood Ratio Orderings in Economics." In: Stochastic Orders and Decision Under Risk: Papers from the International Workshop Held in Hamburg, May 16-20, 1989 (eds. K. Mosler and M. Scarsini), Institute of Mathematical Statistics, Hayward.

[22] Levinson, A., and E. Silva, 2021. "The Electric Gini: Income Redistribution through Energy Prices." Working Paper.

[23] Martimort, D., and L. Stole, 2009. "Market Participation in Delegated and Intrinsic CommonAgency Games." Rand Journal of Economics, 40, 78-102.

[24] Maskin, E., and J. Riley, 1984. "Monopoly with Incomplete Information." Rand Journal of Economics, 15, 171-196.

[25] Miravete, E., 2007. "Limited Gains From Complex Tariffs." Working paper.

[26] Mussa, M., and S. Rosen, 1978. "Monopoly and Product Quality." Journal of Economic Theory, $18,301-317$.

[27] Pigou, A.C., 1920. "The Economics of Welfare.” Macmillan, London.

[28] Ramsey, F. P., 1927. "A Contribution to the Theory of Taxation." Economic Journal, 37, 47-61. 
[29] Rochet, J.-C., and L. Stole, 2002. "Nonlinear Pricing with Random Participation." Review of Economic Studies, 69, 277-311.

[30] Stole, L., 2007. "Price Discrimination and Competition." In: Handbook of Industrial Organization, vol. 3 (eds. M. Armstrong and R. Porter), North-Holland.

[31] Verboven, F., 1999. "Product Line Rivalry and Price Discrimination." Journal of Industrial Economics, 47, 399-426.

[32] Villas-Boas, S. B., 2009. "An Empirical Investigation of the Welfare Effects of Banning Wholesale Price Discrimination." Rand Journal of Economics, 40, 20-45.

[33] Wilson, R., 1993. Nonlinear Pricing. Oxford University Press, Oxford. 